\title{
THE INTERNET OF THINGS IN THE POWER SECTOR OPPORTUNITIES IN ASIA AND THE PACIFIC
}

Arun Ramamurthy and Pramod Jain

NO. 48

August 2017
ADB SUSTAINABLE DEVELOPMENT WORKING PAPER SERIES 
Sustainable Development Working Paper Series

\section{The Internet of Things in the Power Sector Opportunities in Asia and the Pacific}

Arun Ramamurthy and Pramod Jain

No. 48 | August 2017
Arun Ramamurthy provided inputs and jointly developed the working paper. Ramamurthy is a senior public management specialist (ICT and e-governance) at the Asian Development Bank.

Pramod Jain wrote the working paper. Jain is an expert in wind energy with experience in sensors, data analytics, and cloud computing. He provides consulting services to the Asian Development Bank. 
(c) (1)

(C) 2017 Asian Development Bank

6 ADB Avenue, Mandaluyong City, 1550 Metro Manila, Philippines

Tel +632632 4444; Fax +6326362444

www.adb.org

Some rights reserved. Published in 2017

Publication Stock No. WPS178914-2

DOI http://dx.doi.org/10.22617/WPS178914-2

The views expressed in this publication are those of the authors and do not necessarily reflect the views and policies of the Asian Development Bank (ADB) or its Board of Governors or the governments they represent.

ADB does not guarantee the accuracy of the data included in this publication and accepts no responsibility for any consequence of their use. The mention of specific companies or products of manufacturers does not imply that they are endorsed or recommended by ADB in preference to others of a similar nature that are not mentioned.

By making any designation of or reference to a particular territory or geographic area, or by using the term "country" in this document, $A D B$ does not intend to make any judgments as to the legal or other status of any territory or area.

This work is available under the Creative Commons Attribution 3.0 IGO license (CC BY 3.0 IGO)

https://creativecommons.org/licenses/by/3.0/igo/. By using the content of this publication, you agree to be bound by the terms of this license. For attribution, translations, adaptations, and permissions, please read the provisions and terms of use at https://www.adb.org/terms-use\#openaccess

This CC license does not apply to non-ADB copyright materials in this publication. If the material is attributed to another source, please contact the copyright owner or publisher of that source for permission to reproduce it. ADB cannot be held liable for any claims that arise as a result of your use of the material.

Please contact pubsmarketing@adb.org if you have questions or comments with respect to content, or if you wish to obtain copyright permission for your intended use that does not fall within these terms, or for permission to use the ADB logo.

Notes:

In this publication, "\$” refers to US dollars.

ADB recognizes "China" as the People's Republic of China.

Corrigenda to ADB publications may be found at http://www.adb.org/publications/corrigenda 


\section{CONTENTS}

TABLES AND FIGURES

IV

ABBREVIATIONS

EXECUTIVE SUMMARY VI

I. INTRODUCTION

A. Definition of the Internet of Things $\quad 2$

1. Uniquely Identifiable Things 2

2. Sensing and Actuation 2

3. Anywhere, Anytime 2

B. Genesis of the Internet of Things 3

C. The Internet of Things Solution Architecture $\quad 5$

II. THE INTERNET OF THINGS IN THE POWER SECTOR

A. Asset Performance Management 10

B. Operational Optimization 12

C. Comprehensive Customer Services and Experiences 13

D. The Internet of Things in the Power Sector in Asia 14

$\begin{array}{ll}\text { III. CASE STUDIES } & 14\end{array}$

A. Asset Performance Management 14

1. Large European Electric Utility 15

2. Wind Farms in the United States 16

B. Operational Optimization 16

1. Conventional Power Plants 16

2. Optimization of Energy Production in Wind Farms 17

C. Smart Buildings, Smart Meters, and Smart Consumer Applications 17

$\begin{array}{lr}\text { IV. CHALLENGES } & 18\end{array}$

V. WAY FORWARD FOR THE ASIAN DEVELOPMENT BANK 20

$\begin{array}{ll}\text { A. Investment } & 20\end{array}$

B. Capacity Building $\quad 21$

C. Tangibility of Knowledge Solutions $\quad 22$

D. Asian Development Bank's Smart Grid Projects 22

$\begin{array}{lr}\text { VI. NEXT STEPS } & 23\end{array}$ 


\section{TABLES AND FIGURES}

\section{TABLES}

1 Comparison of the State of Current Technologies

2 Case Studies on Use of Internet of Things in Conventional Power Plants for Asset

Performance Management

3 Case Studies on Use of Internet of Things in Conventional Power Plants

4 Case Studies on Advanced Metering Infrastructure Implementation Funded by the United States Department of Energy

5 Illustration of a Structured Methodology for Mapping the Plan, Priorities, and Progress of an Internet of Things Initiative

\section{FIGURES}

1 Illustration of the Four Industrial Revolutions

2 Drivers of Internet of Things

3 Internet of Things as Convergence of the Operational and Information Technologies

4 Components of the Internet of Things

5 The Internet of Things Maturity Model

6 Illustration of the Components of the Internet of Things

7 The Maintenance Maturity Pyramid

8 Benefits of the Internet of Things for Asset Performance Management

9 Phased Value-Driven Approach to Internet of Things Projects 


\section{ABBREVIATIONS}

$\begin{array}{ll}\text { ADB } & \text { Asian Development Bank } \\ \text { ADF } & \text { Asian Development Fund } \\ \text { AMI } & \text { advanced metering infrastructure } \\ \text { APM } & \text { asset performance management } \\ \text { APR } & \text { advanced pattern recognition } \\ \text { CMS } & \text { condition monitoring system } \\ \text { DMC } & \text { developing member country } \\ \text { GIS } & \text { geographic information system } \\ \text { ICT } & \text { information and communication technology } \\ \text { loT } & \text { Internet of Things } \\ \text { IT } & \text { information technology } \\ \text { kWh } & \text { kilowatt-hour } \\ \text { M2M } & \text { machine to machine } \\ \text { MW } & \text { megawatts } \\ \text { MWh } & \text { megawatt-hour } \\ \text { O\&M } & \text { operation and maintenance } \\ \text { PaaS } & \text { platform-as-a-service } \\ \text { PRC } & \text { People's Republic of China } \\ \text { PLC } & \text { programmable logic controller } \\ \text { SCADA } & \text { supervisory control and data acquisition } \\ \text { SEMS } & \text { smart energy management system } \\ \text { T\&D } & \text { transmission and distribution } \\ \text { TCP/IP } & \text { transmission control protocol/internet protocol } \\ \text { UCP } & \text { unit commitment process } \\ & \end{array}$




\section{EXECUTIVE SUMMARY}

The Internet of Things (loT) has the potential to significantly transform the industrial sector. The McKinsey Global Institute predicts that the total potential economic impact of loT will be in the range of $\$ 3.9$ trillion to $\$ 11.1$ trillion per year in 2025 . ${ }^{1}$ On the top end, this would amount to $11 \%$ of the world economy. General Electric (GE)predicts that $\$ 1.3$ trillion of value can be captured in the electricity value chain from 2016 to 2025 globally by loT. ${ }^{2}$

In its simplest form, loT has three components: digitization of assets, collection of data about the assets, and computational algorithms to control the system formed by the interconnected assets. Although there is a lot of hype around loT, the power sector has been the beneficiary of two recognizable early consumer-oriented applications of loT: smart meters and smart thermostats.

In its initial incarnation, smart meters were internet-connected devices to send electricity consumption data to the utility. In newer incarnations, a variety of add-on services have been created, for instance customer services like energy management portal, net metering, prepaid purchase of electricity, and data analytics based services for utilities like outage location, pilferage identification, management of distribution voltage to reduce losses, and others. After the installation of advanced metering infrastructure (AMI), the city of Burbank, California reported $1 \%-2 \%$ reduction in usage per customer, $87 \%$ reduction in field visits to customers, 15 minutes or less response time as opposed to hours or days to metering-related customer requests, and improvement to reliability of grid with drop in System Average Interruption Frequency Index (SAIFI) from 0.34 to 0.24, and System Average Interruption Duration Index (SAIDI) from 27.8 minutes to 9.5 minutes. $^{3}$

Smart thermostats are internet-connected devices that measure temperature and/or humidity inside a home or office and send the data to the cloud. An automated algorithm or an authorized user on a smart phone can change the temperature setting of the thermostat. A variety of machine-learning applications have been developed to balance energy-saving and user-customized comfort. Nest, a leading manufacturer of smart thermostats has reported a drop in electricity bill of 10\%-12\% for heating and about 15\% for cooling. ${ }^{4}$ Extending this concept to large commercial buildings, according to a study conducted by Gartner, an integrated building management system that manages cooling, heating, and lighting can help reduce energy consumption by $50 \%{ }^{5}$

In Asia, several pilots of smart meters, smart buildings, and smart cities are ongoing. Smart meters have the potential to significantly improve customer service and reduce cost through easier payments and better outage management; improve energy access by enabling new business models for providing electricity in off-grid applications. Smart thermostats and smart meters in conjunction with other loT solutions have the potential to spur a variety of smart buildings and smart city applications.

\footnotetext{
McKinsey Global Institute. 2015. The Internet of Things: Mapping the Value Beyond the Hype. https://www.mckinsey.de/files/ unlocking_the_potential_of_the_internet_of_things_full_report.pdf

2 World Economic Forum. 2016. World Economic Forum White Paper: Digital Transformation of Industries: Electricity-prepared in collaboration with Accenture. https://www.accenture.com/t20170116T084450__w_-/us-en/_acnmedia/Accenture/ Conversion-Assets/WEF/PDF/Accenture-Electricity-Industry.pdf

3 Government of the United States, Department of Energy. 2014. Municipal Utilities' Investment in Smart Grid Technologies Improves Services and Lowers Costs. https://www.smartgrid.gov/files/B4-revised-10-03-2014-100614.pdf

4 M. Rogers. Nest. 2 February 2015. https://nest.com/blog/2015/02/02/the-nest-learning-thermostat-saves-energy-heresthe-proof/

5 Gartner. 2016. Gartner Predicts that by 2020, Half of Smart City Objectives Will Include Climate Change, Resilience and Sustainability KPIs. http://www.gartner.com/newsroom/id/3507317
} 
More recently, loT solutions are entering the domain of industrial operations. In the power sector, the most popular application in this category is condition monitoring and predictive maintenance of a wide variety of assets. The loT-based approach transitions from traditional reactive and periodic maintenance strategies to proactive strategies. The applications are focused on the highest value assets in generation plants, and in the transmission and distribution grid. In this application of loT, assets are continuously monitored with sensors, the collected data is sent to the cloud where a variety of machine learning and artificial intelligence algorithms are used to predict the health and impending failure of the assets, and determine the optimal time to perform maintenance.

In Asia, many grids are plagued with unreliable service. This is primarily because of aging equipment; poor maintenance; and in many cases, the struggle to upgrade power systems to keep up with very high annual demand growth rates. Investment in loT for both existing and new equipment has the potential to significantly reduce unscheduled downtime by identifying problems before they occur, thereby improving reliability and reducing costs. According to the Asian Development Bank (ADB) publication Energy Outlook 2013, Asia and the Pacific will require a cumulative investment of about $\$ 11.7$ trillion in the energy sector to meet business as usual (BAU) energy demand from 2010 to 2035. Demand side investments (additional to BAU case) of $\$ 7.3$ trillion will be required to deploy advanced energyefficient technologies for transport, residential, commercial, and industrial sectors.

Other applications of loT are optimal use of generation assets to increase the efficiency of production. In conventional power plants, loT would be used to tune the operation of a power plant in real time and to balance production with life cycle cost of maintenance and life of equipment. As an example, GE has launched digital power plant systems for gas and coal plants. GE claims its digital technologies when applied to new coal and gas fired power plants can increase fuel efficiency by $3 \%$, power output by $2 \%$, and reduce unplanned downtime by $5 \%$, operation and maintenance costs by $25 \%$, and fuel consumption during starts by $20 \% .{ }^{6}$ In Asia, these strategies may be used to reduce cost of electricity production and emissions.

Another good example of loT use for optimization of operations is in the wind power industry where (i) wake losses are reduced in a wind farm by adjusting pitch and yaw angles of individual turbines, (ii) turbines production is increased above rated value in a controlled manner as long as the stress and fatigue loading are within acceptable limit, and (iii) settings of individual turbines are optimized to local conditions to increase output. GE claims a 5\% to $10 \%$ increase in annual energy production with these strategies. ${ }^{7}$

A futuristic application of loT is a holistic optimization of the entire power network with the goal of decentralization and defossilization of the power sector. IoT has the potential to achieve such a transformation in which (i) renewable energy is generated close to load centers; (ii) energy storage devices are used to store excess energy and deliver energy during periods of high demand; (iii) demand response is used to balance supply and demand; (iv) flexible centralized fossil fuel-based power plants plan production based on real-time predictions of variable renewable generators; and ( $v$ ) dispatch logic, and controllers are used to manage the flow of power. Several of these transformations are being tested in a number of pilots in island grids in Asia with the goal of achieving close to 100\% renewable energy in the power sector and loT will be a key enabler.

6 General Electric. GE Power Digital Solutions. https://www.ge.com/digital/sites/default/files/GE\%20Power\%20Digital\%20 Solutions\%20Brochure.pdf

7 P. Dvorak. 2016. GE Renewable Energy Introduces New Suite of Digital Wind Farm Apps. Windpower Engineering and Development. 
There are several challenges to the adoption of loT in Asia and the Pacific. The following list summarizes the challenges and the way forward:

(i) Financial constraints. A large amount of investment would be required to modernize the energy infrastructure in Asia and the Pacific to achieve the benefits of loT. It should be noted that this investment is much less than the larger infrastructure investment. loT investment should be done alongside new infrastructure investments. For existing equipment, the balance sheet of many utilities may not be healthy for market-based financing of loT projects, therefore it may be impossible to structure results-based or outcome-based vendor or commercial financing for the IoT projects. ADB has worked with and invested in state-owned utilities since its founding. It is therefore in a unique position, using results-based lending, sovereign lending and other financial vehicles, to enable the loT transformation, thereby assisting the utilities toward achieving higher reliability, efficiency, and customer satisfaction.

(ii) Policy impediments. The power subsidy policy in many countries in Asia and the Pacific disincentivizes market-based investment in energy infrastructure. In addition, there is political pressure to keep electricity rates low and employ large numbers of people. These are not conducive to increasing efficiency through loT driven automation. ADB-funded development interventions such as technical assistance programs and loans may be a vehicle for these countries to develop an loT transformation road map that is based on best practices and lessons learned from similar initiatives (e.g., telecommunications, online banking, online retailing, and others).

(iii) Capacity limitations. Strong information and communication technology and analytics skills would be required to fully realize the benefits of loT, and these skills may not be readily available in these countries. Furthermore, strong capability would be required to implement business transformation of the magnitude required by loT projects to gain higher efficiencies and reliability, and overall lower cost. Given these requirements, an loT road map should have capacity building and knowledge transfer as one of the focus areas so that skills development is an essential part of the transformation. 


\section{INTRODUCTION}

"Electricity changed nearly everything about the way we live and work-and that scale of transformation is possible with the Internet of Things." lan Goldin, Director of Oxford Martin School, University of Oxford

The fourth industrial revolution is upon us. Figure 1 illustrates the progression of this revolution. In the prior three revolutions, there were tremendous improvements in productivity-first came steam and water, next came electricity and assembly lines, and then computerization. ${ }^{1}$ The fourth industrial revolution is being led by the Internet of Things (loT), which is leveraging the internet and computing infrastructure to connect machines, appliances, and people. The World Economic Forum initiative describes loT as leading to transformative change: altering the basis of competition, redrawing industry boundaries, and creating a new wave of companies to serve the needs of existing productive assets and services. ${ }^{2}$

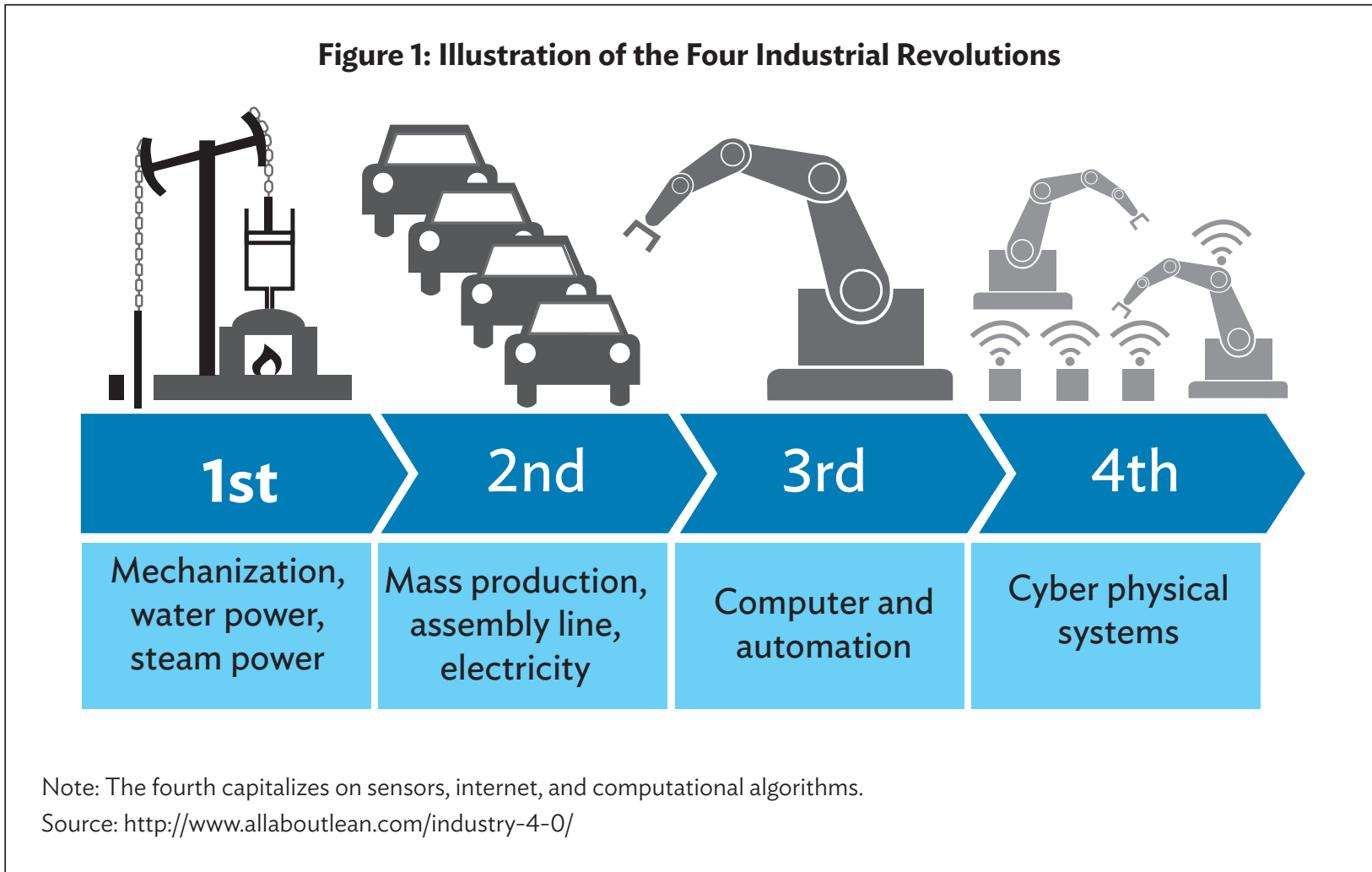

With large-scale deployment of loT, unprecedented volumes of data from connected products will be generated, and the ability to automate decision-making and resulting actions in real time can translate technology transformation into business opportunities. Experts agree that at least four main trends will emerge:

(i) higher operational efficiencies,

(ii) new connected ecosystems coalescing around software platforms,

B. Marr. 2016. Why Everyone Must Get Ready for the 4th Industrial Revolution. Forbes. 5 April. https://www.forbes.com/ sites/bernardmarr/2016/04/05/why-everyone-must-get-ready-for-4th-industrial-revolution/

2 World Economic Forum. 2015. Industrial Internet of Things: Unleashing the Potential of Connected Products and Services. http://www3.weforum.org/docs/WEFUSA_Industriallnternet_Report2015.pdf. 
(iii) greater collaboration between humans and machines, and

(iv) pronounced shift from selling products and/or services to selling measurable outcomes.

The total loT market size in 2015 was $\$ 900$ billion and is projected to grow to $\$ 3.7$ trillion in $2020 .^{3} \mathrm{It}$ also states that loT is projected to have a potential economic impact of $\$ 3.9$ to 11.1 trillion per year in 2025. According to GE, 50 billion assets (devices) will be connected to the internet by 2020 and the investment will top $\$ 60$ trillion during the next 15 years. ${ }^{4}$ The 6.4 billion loT devices in 2016 is predicted to rise to 20.8 billion by $2020 .^{5}$ Although these figures may not be exact, industry stalwarts have a very optimistic view of the loT opportunity.

\section{A. Definition of the Internet of Things}

The Institute of Electrical and Electronics Engineers (IEEE) took on the task of reviewing definitions created by various organizations and individuals, and created a definition of loT: 6

An loT is a network that connects uniquely identifiable 'Things' to the Internet. The 'Things' have sensing/actuation and potential programmability capabilities. Through the exploitation of unique identification and sensing, information about the 'Thing' can be collected and the state of the 'Thing' can be changed from anywhere, anytime, by any thing.

The concepts contained in the definition are described below:

\section{Uniquely Identifiable Things}

The "thing" refers to a physical object that is relevant from the perspective of a user of application. "Uniquely identifiable" refers to the assignment of a unique address on the internet to the "thing" so that it can send data to and receive data from other objects on the internet. The "thing" is therefore a node on the internet with an internet protocol (IP) address and uses it for communication.

\section{Sensing and Actuation}

The sensors and or actuators are connected to the "thing" and perform the sensing and or actuation, which bring the smartness of the "thing."

\section{Anywhere, Anytime}

Ubiquity is a major feature of an loT system, indicating a network that is available anywhere and anytime. But in the context of loT, the concept "anywhere" need not necessarily refer to "globally" and "anytime" to "always." The "anywhere" mainly refers to the concept of where it is needed and the "anytime" similarly refers to when it is needed.

3 C. Ip. 2016. Internet of Things: The loT opportunity-Are You Ready to Capture a Once-in-a-Lifetime Value Pool? Paper presented at the IOT Conference, 21 June, Hong Kong, China. McKinsey\&Company.

4 General Electric. GE Power Digital Solutions. https:/www.ge.com/digital/sites/default/files/GE\%20Power\%20Digital\%20 Solutions\%20Brochure.pdf

5 Gartner. 2015. Gartner Says 6.4 Billion Connected “Things” Will Be in Use in 2016, Up 30 Percent From 2015. 10 November. http://www.gartner.com/newsroom/id/3165317

6 R. Minerva, A. Biru, and D. Rotondi. 2015. Towards a Definition of the Internet of Things (loT). http://iot.ieee.org/images/files/ pdf/IEEE_loT_Towards_Definition_Internet_of_Things_Revision1_27MAY15.pdf 
A more verbose and layman definition of loT is from a 1999 speech of Kevin Ashton of Massachusetts Institute of Technology, who first coined the term loT:?

Today computers, and, therefore, the Internet, are almost wholly dependent on human beings for information. Nearly all of the roughly 50 petabytes (a petabyte is 1,024 terabytes) of data available on the Internet were first captured and created by human beings by typing, pressing a record button, taking a digital picture or scanning a bar code. The problem is, people have limited time, attention, and accuracy. All of which means they are not very good at capturing data about things in the real world. If we had computers that knew everything there was to know about things, using data they gathered without any help from us, we would be able to track and count everything and greatly reduce waste, loss and cost. We would know when things needed replacing, repairing or recalling and whether they were fresh or past their best.

A more recent layman definition is from McKinsey: ${ }^{8}$

We define the Internet of Things as sensors and actuators connected by networks to computing systems. These systems can monitor or manage the health and actions of connected objects and machines. Connected sensors can also monitor the natural world, people, and animals.

\section{B. Genesis of the Internet of Things}

As with all revolutions, loT rests on the shoulders of a variety of past technologies. The global positioning system (GPS) was one of the earliest loT devices. GPS-guided navigation in smartphones is becoming ubiquitous with aggregation of data from multiple sources to detect congestion, and the intelligence to compute efficient routes. It is an illustrative example of the convergence of GPS sensors, satellites, communication networks, geographical information systems, and smart algorithms in the cloud, to work toward making navigation possible. Fast forward a few years and now the prime example of loT is the autonomous car, which was inconceivable a decade ago but is almost a reality now. Using this example, the concept of IoT can be encapsulated as the capability to sense location and surrounding environment (in this case, it is other vehicles, pedestrians, curbs, traffic signals, etc.) with a multitude of sensors, process all the data, make intelligent decisions, and act in real time.

Sensors, control systems, feedback loops, communication technologies, artificial intelligence, and other components of loT have been in existence for a long time. Higher efficiencies, new capabilities, and better experiences were also desired as essential since the beginning of the industrial revolution, if not since the beginning of the human endeavor. The question is what has changed and why now? There are three precursors that provide an answer to the question (Figure 2):

(i) Inexpensive and high power chips. The volumes associated with the cell phone industry has provided sharply lower prices for $\mathrm{Wi}$-Fi chipsets, wireless chipsets, and a wide variety of sensors like accelerometers, cameras, tactile, sound, temperature, and others.

(ii) Standardization. Communication using the 3G, 4G, and 5G cellular networks, TCP/IP protocol and addressability of large numbers of devices using IPv 6 were standardized.

7 K. D. Foote. 2016. A Brief History of the Internet of Things. Dataversity. 16 August. http://www.dataversity.net/brief-historyinternet-things/

8 J. Manyika, M. Chui, P. Bisson, J. Woetzel, R. Dobbs, J. Bughin, and D. Aharon. 2015. The Internet of Things: Mapping Value Beyond the Hype. McKinsey Global Institute. 


\section{Figure 2: Drivers of the Internet of Things}

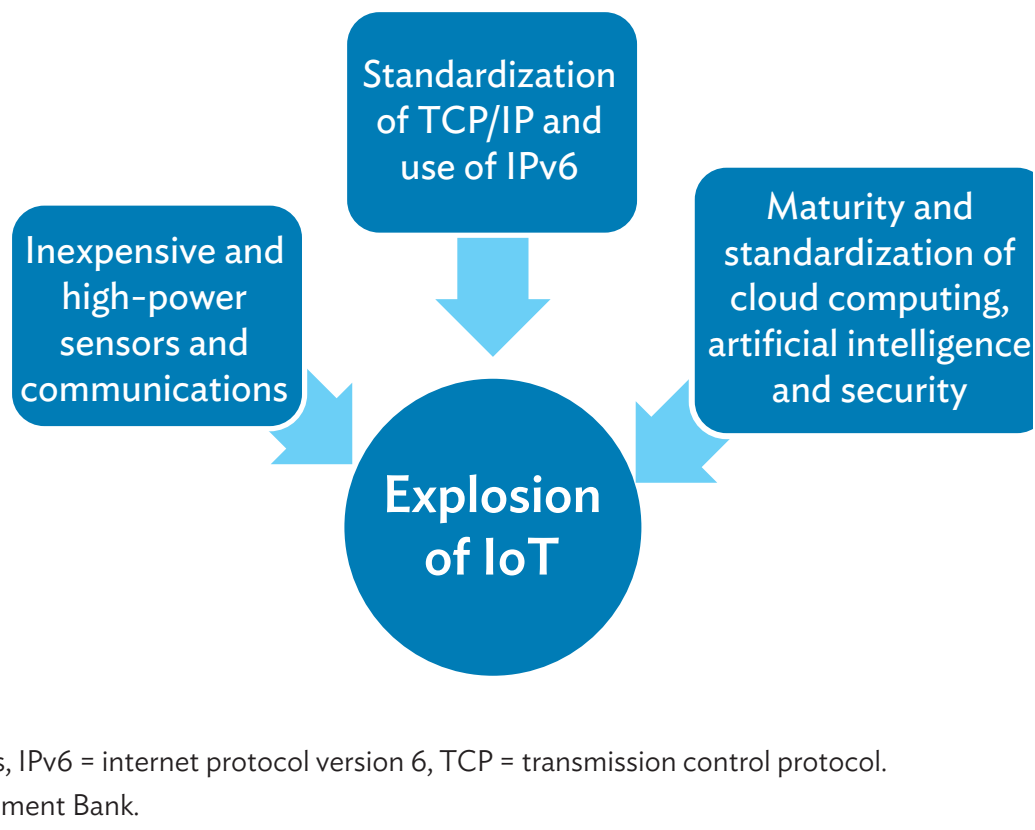

Source: Asian Development Bank.

(iii) Maturity and standardization of software technologies. These include artificial intelligence (AI), cloud computing, and cyber-security. Rapid adoption of smart devices and services that use $\mathrm{Al}$ technologies in the consumer space for voice recognition-based virtual assistant (Siri, Alexa, Cortana, Google Assistant, and others), face recognition, driverless cars, algorithmbased financial advisor and others are leading to diffusion of this technology to other domains. Rapid adoption of cloud computing is providing infrastructure as a service, platform as a service (PaaS), and software-as-a-service in a consolidated and cost effective manner. Both these software trends are making it easier and inexpensive to build loT solutions.

In the past, the cost of loT solutions was high because of the high cost of hardware devices, custom communication protocol, custom software, high cost of in-house redundant infrastructure for computing and storage, and others. In each of these items there has been a significant reduction in cost and increase in performance, which has led to a sustained emergence of loT.

Table 1 compares the current state with future vision of loT.

Industrial loT has been characterized as a convergence of enterprise ICT and operational technology (Figure 3). ${ }^{9}$ This is another perspective of loT. Operational technology like process logic controller (PLC), process automation, and supervisory control, and data acquisition (SCADA) systems are widely used for factory and process automation, to improve yield, quality, and efficiency. Enterprise IT has seen huge advances with resource planning, customer relationship management, decision support systems, and others to manage the value chain, reduce cost, and improve customer service. However, the two systems have not been merged in a meaningful way to fully realize the objectives of a business.

\footnotetext{
9 P. Daugherty, P. Banerjee, W. Negm, and A. E. Alter. 2015. Driving Unconventional Growth through the Industrial Internet of
} Things. Accenture. 
Table 1: Comparison of the State of Technologies
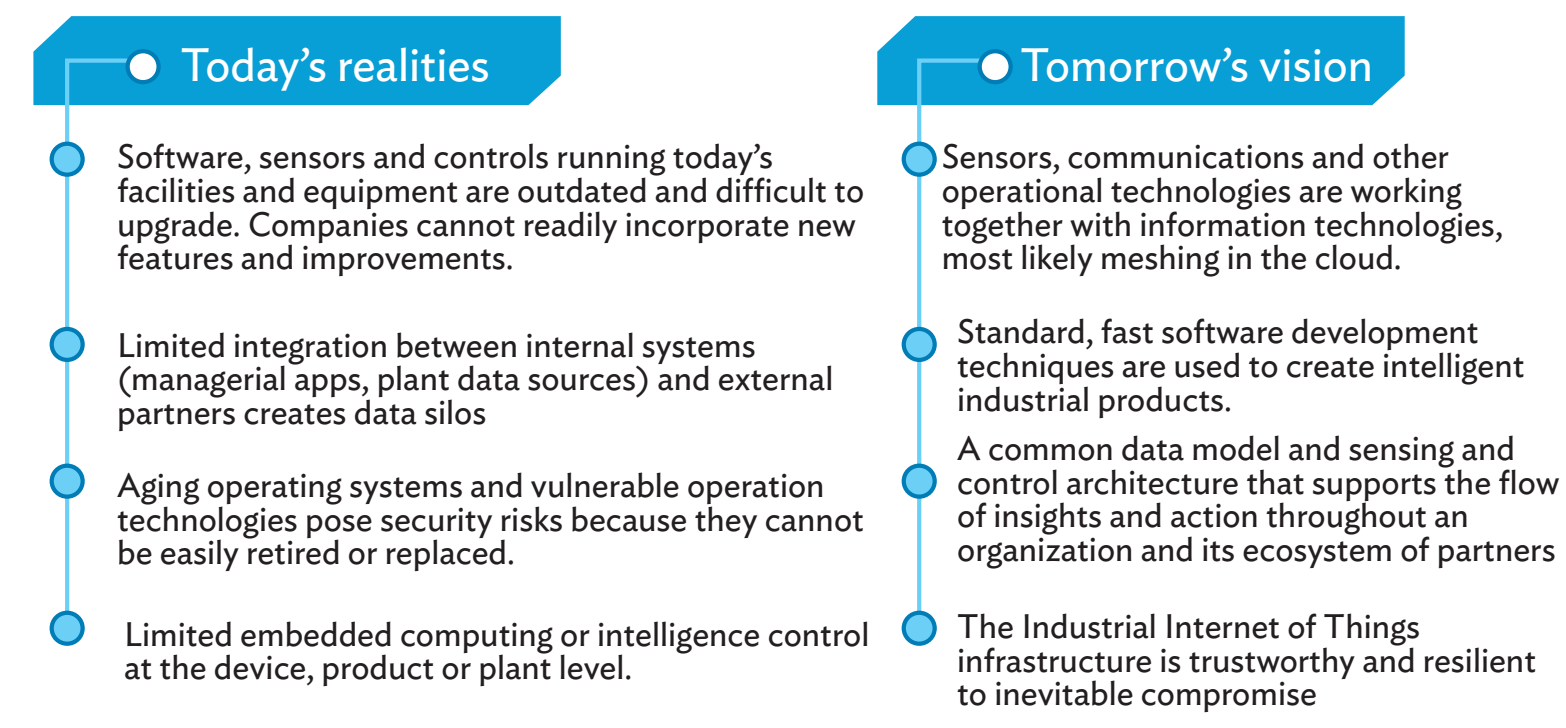

Source: Accenture. Winning with the Industrial Internet of Things: How to Accelerate the Journey to Productivity and Growth. https://www.accenture.com/us-en/insight-industrial-internet-of-things

Figure 3. Internet of Things as Convergence of Operational and Information Technologies

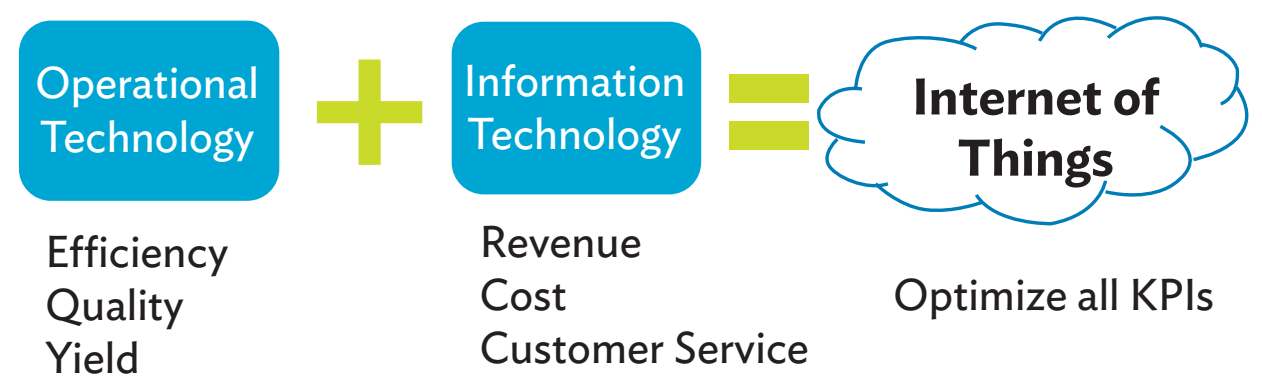

$\mathrm{KPIs}=$ key performance indicators.

Source: World Economic Forum, “Industrial Internet of Things.” http://wwwe.weforum.org/docs/WEFUSA_ Industriallnternet_Report2015.pdf

\section{The Internet of Things Solution Architecture}

A typical loT solution architecture contains the five components shown in Figure 4. The first component is edge devices, which is a collection of disparate devices and technologies. These devices are used to measure the state of assets, collect the data, perform data aggregation and limited analytics, and send to gateway devices. Aside from this first component, the loT industry has standardized on a cloud-based PaaS architecture for the remaining four components. IBM-Bluemix-IoT, GE Predix, Microsoft Azure-loT and SAP HANA-loT are examples of PaaS customized for loT. The five components are described below:

(i) Edge devices. These consist of a wide variety of sensors, barcode devices, hand-held devices and others that capture data in the field about assets. These devices generate real-time data. The 
most common sensors used in loT include temperature, accelerometer, oil condition, oil wear debris, acoustic emission, motion, light, sound, camera, and others. Depending on the asset that is being monitored and the sensors deployed to monitor the asset, the amount of data generated by sensors can be very large-hundreds of kilobytes per second, which in a few months adds up to terabytes of data. Therefore, this raw sensor data is processed and aggregated at a gateway device (like a data logger), and then sent to the loT platform.

(ii) IoT hub. This is the entry point for the data into the platform and exit point for all commands to actuators. The loT hub performs a variety of security tasks like device identity management, authentication, data decryption and/or encryption, and others. The loT hub manages two-way data and event communication-device to cloud and cloud to device.

(iii) Storage. The incoming datasets are stored in a variety of data storage methods. The method chosen for a dataset is primarily determined by the volume of data and the analytics.

(iv) Analytics. A variety of data analytics is performed on the data. These modules are available as software-as-a-service on the cloud platform. Stream analytics is a class of modules for real time analytic computations on streaming data from sensors and events. Machine learning is another class of modules or algorithms that use historical data to learn about patterns and then to recognize patterns in new data. A variety of other physics-based and statistics-based artificial intelligence algorithms are used for prediction and decision making.

(v) Actions and Presentation. The final component of the loT cloud platform contains a variety of applications, dashboards, integration with ERP applications, and a variety of alerts, notifications, and decisions. For instance, in a predictive maintenance application, the action may look like a decision to put an asset in maintenance; in a smart building application, the action may be to change the set temperature of heating, ventilation, and air conditioning (HVAC) by -2 , which is sent to the HVAC unit using cloud-to-device communication.

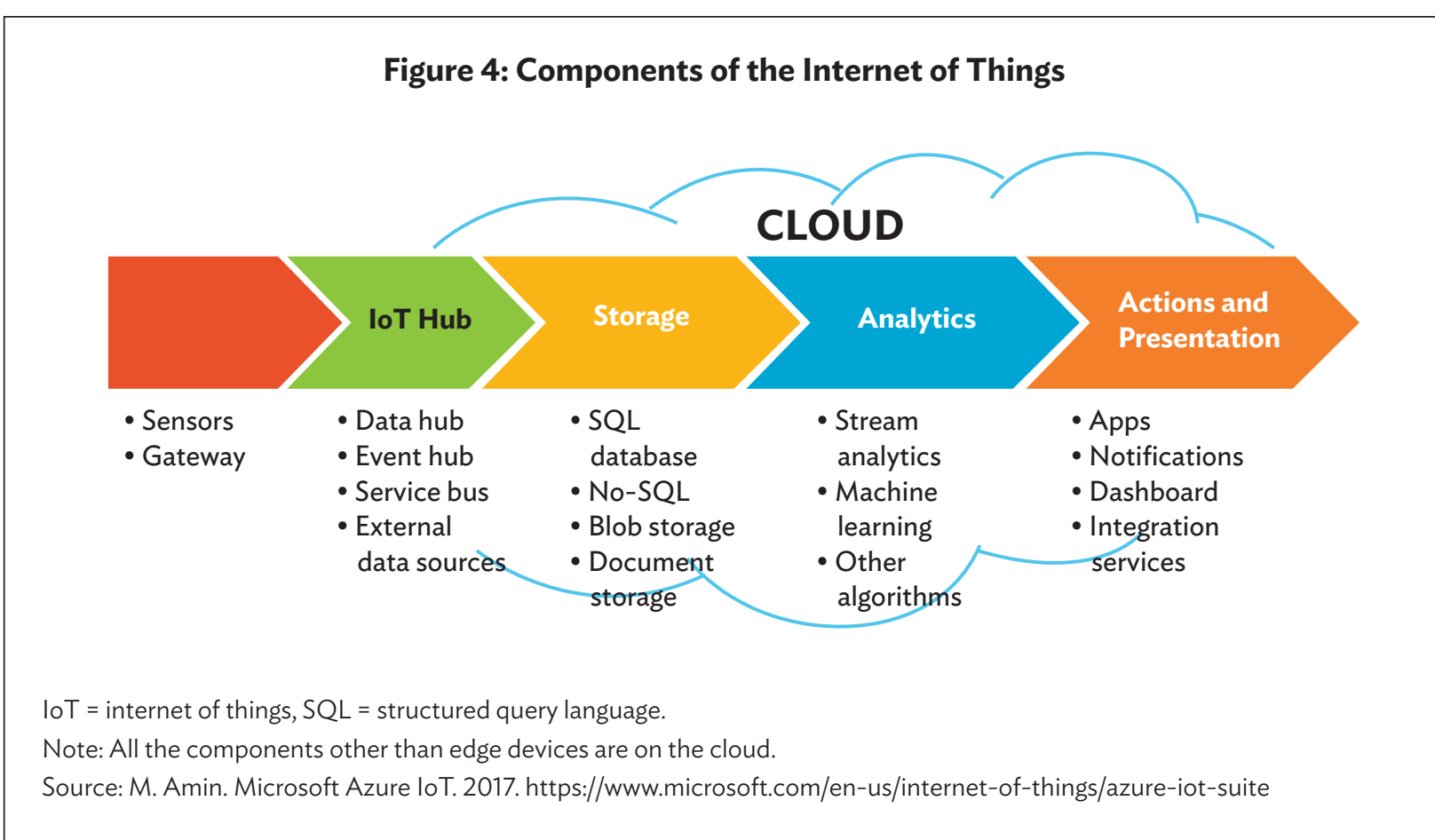




\section{THE INTERNET OF THINGS IN THE POWER SECTOR}

Supervisory control and data acquisition systems gained popularity in the power sector in the 1990s as means to automate industrial processes. It was an early version of the loT. Its functions included supervision of the operation of programmable logic controllers (PLCs) by collecting data about the underlying process, analyzing the data, and sending commands to control the processes. Smart meters are another early example of loT, with its ability to deliver near real-time consumption data and connect and/or disconnect customers, both without visiting the customer location. In the continuum of loT maturity (Figure 5), both solutions do monitor and control. Often, operational technology like SCADA and smart meters have to be complemented with information and communication technology (ICT) like geographic information systems (GIS) and enterprise resource planning (ERP) systems for an loT solution to move up to a higher level of maturity. A few examples of loT solutions with a higher level of maturity are described next.

\section{Figure 5: The Internet of Things Maturity Model}

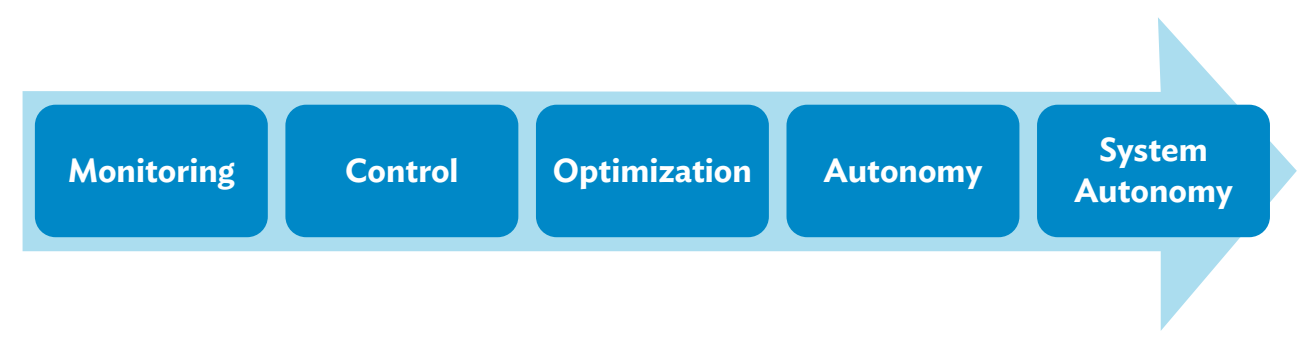

Note: The internet of things starts from monitoring and then control of equipment and processes. Next is optimization, followed by equipment running autonomously adjusting to environmental conditions. Finally, system autonomy is communicating with other things to optimize performance.

Source: Ericsson, Monitor, Deloitte, "Everything connected: A study of adoption of Internet of Things among Danish companies" http://digital.di.dk/SiteCollectionDocuments/Analyser/loT_Report_onlineversion.pdf

An example of an underlying process controlled by SCADA is burning of fuel, generating steam, and generating power using a turbine. Until recently, it was costly to put enough sensors, transmit highfrequency data, store the large volume of data, perform smart analytics on the data, and tune the process for optimal performance. These constraints are being overcome and a "full digitalization" of the process is being unleashed by loT. Continuing with this example, examine the entire generation to consumption process in the power sector:

(i) The generation process can be made flexible by loT and hence it can support efficient operation at various capacity factors as opposed to always operating in baseload mode. This flexibility is essential to integrating higher amounts of renewable power.

(ii) loT with advanced analytics can accurately forecast solar and wind generation, which would allow conventional generators sufficient time to ramp up or down thereby reducing emissions of the power sector.

(iii) Advanced metering infrastructure with automated demand response would allow utilities to reduce demand and as a result, minimize use of expensive and highly polluting peaker plants, and maximize the penetration of renewable energy. 
(iv) When there is a generator trip, ICT can provide data about which customers will be affected (through a geographic information system [GIS] and a customer information system), how much energy should be bought from neighboring utilities versus from peaking generators and if there is need for repairs, what is the level of the spare parts inventory.

The convergence of IT and operational technology therefore provides significant opportunities for optimization. Consider a second example of work management, in which a truck with crew rolls out to fix a problem at a pole (Figure 6):

\section{Figure 6: Illustration of the Components of the Internet of Things}

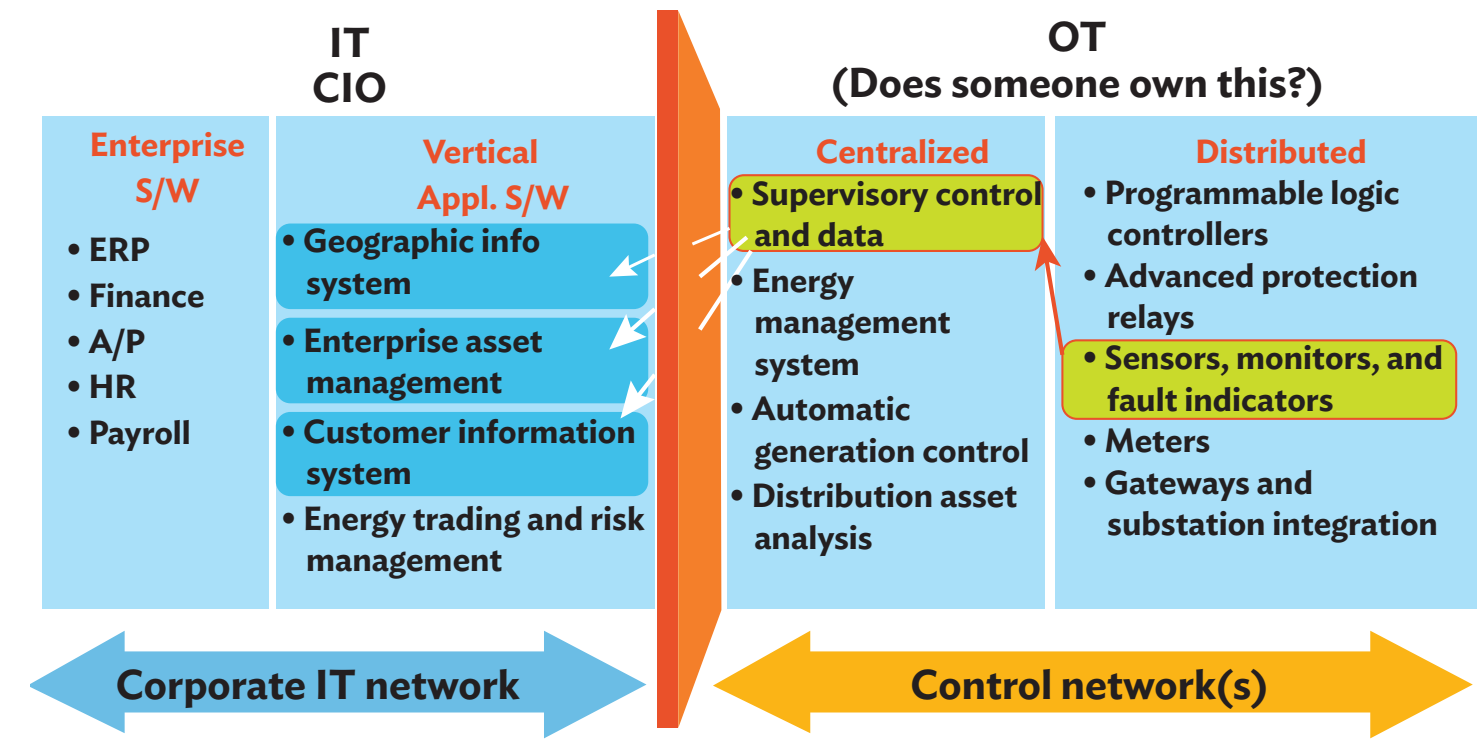

$\mathrm{CIO}$ - chief information officer, OT - operational technology, ERP- enterprise resource planning, A/P-accounts payable, HR- human resource

Source: Gartner. 2008. Overview: IT and OT: Intersection and Collaboration. https://www.gartner.com/doc/766920/overviewit-ot-intersection-collaboration

(i) Operational technology components like smart meters and other line sensors provide near real-time information, which can be combined with IT accessories like GIS to pinpoint the location of the problem.

(ii) IT systems can inform the crew of spares and sensors that are required but not on the truck to complete the job.

(iii) IT applications on a tablet or laptop can provide locations of assets like switch gear, relays, and other equipment on a map that need to be managed before work can begin on the line.

(iv) Operational technology can provide direction of flow of power and voltages in neighboring buses to the IT system (GIS-based map on tablet).

IoT can therefore enable the crew to efficiently and safely repair and restore the circuit. 
IoT has enabled a transformation in which much more than supervision and control of the process associated with generation and delivery of power is accomplished. Consider the following three applications:

- Increase the efficiency and reliability of assets. This can be accomplished with loT-enabled operation and maintenance (O\&M) on generation, and transmission and distribution (T\&D) assets. On the operations end, loT can reduce fuel consumption and emissions, and increase flexibility of generation by lowering minimum capacity factor and increasing ramp rate. In the Asian context, the following are examples of loT projects that can lead to meeting the double objectives of lower cost and lower emissions: (i) automatic generation control that takes into account economics and emissions; (ii) reduce technical losses in T\&D network through active voltage management, installation of actuators on smart transformers; and (iii) reduce nontechnical losses using a network of smart meters. On the maintenance end, loT can play an important role in condition monitoring and predictive and proscriptive maintenance of assets. In the Asian context, loT can help by moving a utility to transition from running assets until failure or performing schedule maintenance (see Figure 7: bottom two levels of the pyramid) to conducting predictive and proscriptive maintenance to reduce cost and improve reliability.

\section{Figure 7: The Maintenance Maturity Pyramid}

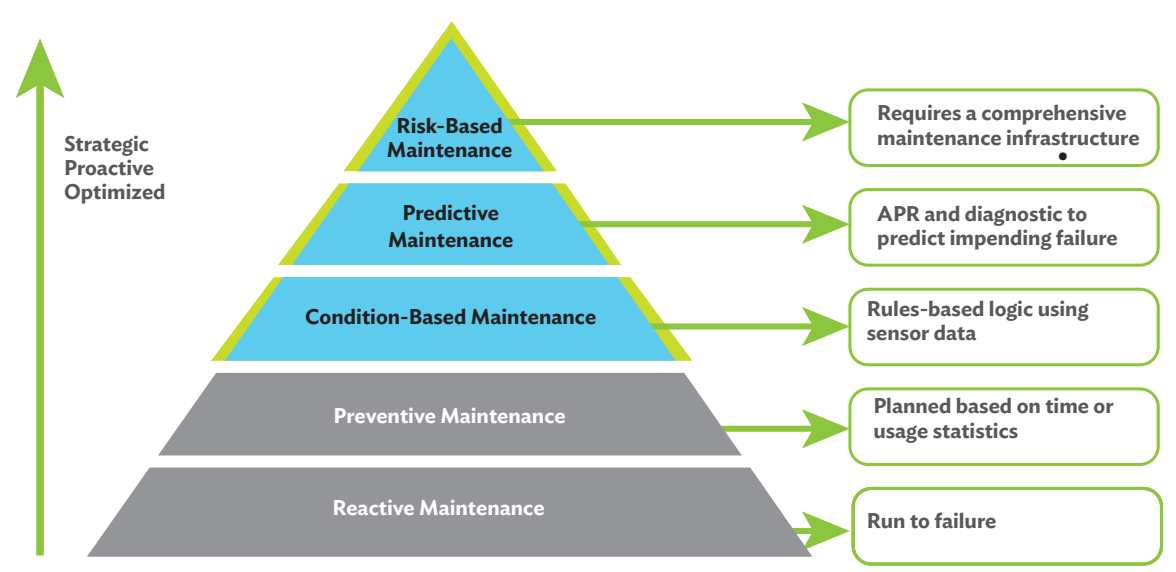

APR $=$ advanced pattern recognition .

Note: The Internet of Things enables the top three types of maintenance strategies.

Source: Schneider Electric Software. 2015. http://software.schneider-electric.com/pdf/application-solution/enterprise-assetperformance-management-for-power/

- Grid optimization with large penetration of renewables and storage. In Asia, utility-scale wind and solar plants are being curtailed because of inflexibility of generation and demand. loT can accomplish flexibility in generation and demand thereby reduce the amount of curtailment of clean power sources like wind and solar, thereby increase the ability to fully realize reduction in greenhouse gas emissions from higher penetration of variable generation.

- Enable consumers to be energy-efficient. loT can significantly improve the efficient use of electricity while enhancing the level of comfort, by providing customers access to near real-time information about usage and peak events; and, machine learning algorithms to make smart decisions. Within a home or building this can enable customers to manage time of day consumption; turn on or off devices; and make decisions about buying, selling, or storing energy; all of which may occur with limited or no involvement of the established power utility. 
General Electric (GE) predicts that in the electricity value chain $\$ 1.3$ trillion of value can be captured during 2016 to 2025 globally by loT. This value is from deployment of smart devices, cloud computing, advanced analytics, advanced dashboard, and the overall integration of all these services into a platform. According to $\mathrm{GE}$, the $\$ 1.3$ trillion value will be derived from the following three areas: ${ }^{10}$

(i) Asset performance management would contribute $\$ 387$ billion in value. This is derived from lower repair and maintenance cost, lower downtime of assets, and fewer critical breakdowns.

(ii) Operational optimization and aggregation would contribute $\$ 445$ billion in value. This is derived from real-time supply and demand platform, real-time network controls, energy aggregation platform, and connected and interoperable devices

(iii) Comprehensive customer services would contribute $\$ 438$ billion in value. This is derived from digitizing customer interactions and smart energy management services.

In addition to the $\$ 1.3$ trillion value capture by the industry, more than $\$ 2$ trillion in societal benefits will be realized through loT, which include reduction in carbon emissions, new job creation, and value creation for consumers.

The focus of this report is primarily on loT solutions that address the above three opportunities in the power industry. The section starts by describing the three opportunities. Each category of loT opportunity will be described as it pertains to the three verticals-generation, transmission and distribution, and consumption-followed by the holistic impact across the three verticals.

\section{A. Asset Performance Management}

Asset performance management (APM) is one of the most prevalent use-cases of industrial loT. The power sector in Asia suffers from high levels of inefficiency and unreliability as a result of poor maintenance coupled with age of the equipment. The current status of $O \& M$ in the power industry can be summarized in these observations by ABB: ${ }^{11}$

(i) The average age of assets is $40+$ years.

(ii) The assets are expensive, large, and difficult to replace.

(iii) Historical data about assets is not centralized and in disparate systems.

(iv) A large number of experts are reaching retirement age, and they are not being replaced and trained.

(v) As monolithic utilities are deregulated, privatized, or converted to autonomous entities, O\&M budgets are being cut.

Given this state, the impact of loT on APM can be significant. The loT solution for an APM process is the same as in Figure 4. The Schneider maintenance maturity pyramid describes how loT is transforming APM to be more strategic, proactive, and optimized. ${ }^{12}$ Without loT, an organization would do reactive or preventive maintenance. With loT, instead of spending O\&M budget to perform scheduled maintenance

10 World Economic Forum in Collaboration with Accenture. 2016. World Economic Forum White Paper: Electricity Industry.

11 ABB. 2014. Taking the First Steps toward Condition-Based Maintenance. ABB White Paper. http://new.abb.com/docs/librariesprovider139/default-document-library/wp-2_first_steps_to_condition_maint_wp.pdf?sfvrsn=2

12 Schneider Electric Software. 2015. http://software.schneider-electric.com/pdf/application-solution/enterprise-assetperformance-management-for-power/ 
at fixed intervals on all units, the focus can now be on where it is needed the most based on condition, predicted time to failure, and risk of failure. The following three O\&M strategies are enabled by loT:

(i) condition-based maintenance, in which patterns in sensor data are identified to plan maintenance of the asset;

(ii) predictive maintenance, in which trends in sensor data are identified to predict time to failure, which is impending failures and problems are identified, which guides predictive maintenance; and

(iii) risk-based maintenance, in which decision about maintenance of an asset is also based on optimizing the use of maintenance of resource across all assets. In this approach, the risk of failure is used as the metric to allocate maintenance resources. Risk here means the product of probability of failure and the economic consequences of failure.

A transition from reactive maintenance to loT-enabled proactive maintenance is illustrated in Figure 8. This approach has the following advantages:

(i) improved reliability and availability of the assets;

(ii) reduced cost of maintenance;

(iii) significant reduction or elimination of unplanned downtime, hence no expensive emergency repairs and lost productivity;

(iv) replacement of schedule preventive maintenance with predictive maintenance and risk-based maintenance thereby increasing availability and reducing cost;

(v) lower inventory of spare parts for emergency repairs; and

(vi) higher productivity and safety of repair crews due to identification of source of failure.

\section{Figure 8: Benefits of the Internet of Things for Asset Performance Management}

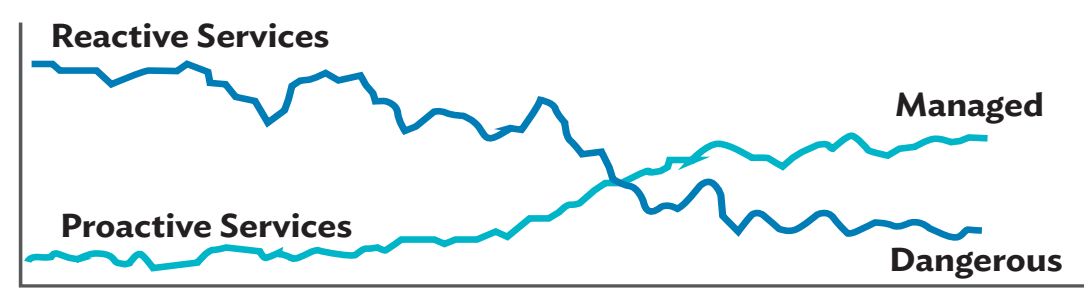

$\begin{array}{ll}\text { Improper balance } & \text { Proper balance } \\ \text { - Expensive } & \text { - Service tailored to need } \\ \text { - Unpredictable } & \text { - Predictable } \\ \text { - Something will break } & \text { - Fix before failure } \\ \text { - Customer must define } & \text { - Higher reliability } \\ \text { good } & \text { - Reduce downtime } \\ \text { - Extended downtime } & \text { - Normal parts ordering } \\ \text { - Rush parts order } & \text { - Scheduled service } \\ \text { - Schedule correction } & \text { - Planned downtime } \\ \text { - Unplanned downtime } & \end{array}$

Note: The number of reactive maintenance is replaced with proactive maintenance.

Source: ABB. 2014. Taking the First Steps Toward Condition-Based Maintenance. ABB White Paper. http://new.abb.com/docs/ librariesprovider139/default-document-library/wp-2_first_steps_to_condition_maint_wp.pdf?sfvrsn=2 
Thus far, the focus was on generation assets, but APM applies to all assets, including transmission and distribution assets like transformers, switch gear, capacitors, insulators, conductors, and others. These assets suffer from electrical breakdown due to material degradation and mechanical deformations. The dielectric and thermal material degradations are primarily due to aging, overvoltages, and thermal overheating. Mechanical deformations are caused by short-circuit faults. IoT sensors can provide data about the health of these assets in order to improve grid reliability and reduce cost of repairs.

\section{B. Operational Optimization}

Compared to APM, the potential of IoT solutions in operational optimization of power plant assets has been marginally explored. Power plants in a grid have to meet stringent requirements for frequency control, voltage control, dispatch control, automatic generation control, ramp rate, and others. To meet these requirements, generators in plants have to precisely follow the load set points provided by the control systems. With variable generation in the mix (wind and solar), the balancing act of managing many generators becomes difficult especially because of the short response time requirements. For balancing, grids rely on inefficient peaking plants and/or running generators at set-points where fuel efficiency is low and emissions are high. Another large source of inefficiency is losses in the transmission system. The power grid is a dynamic system with variability in loads and production level of renewable power plants, which causes changes to power flow across the transmission network. This changes voltage levels at grid nodes causing changes to flow of current, and changes to active and reactive power losses. In addition, with variable generation, there is need for active congestion management of the T\&D network. Optimizing this dynamic network of power plants and T\&D network is impossible without realtime data from all elements of the network. loT can play an important role in this regard-digital power plants, digital substations, and other data collection systems can fill this gap. According to GE, a new digital 500-megawatt power plant can save $\$ 230$ million over the lifetime of the plant, and an existing power plant of the same size can save $\$ 50$ million. ${ }^{13}$ This savings is from $3 \%$ higher fuel efficiency, $2 \%$ higher output, $20 \%$ less fuel on starts, $6 \%-9 \%$ reduction in carbon dioxide emissions, $10 \%$ reduction in nitrogen oxides, $5 \%$ reduction in unplanned downtime, and $25 \%$ reduction in O\&M costs.

Most countries in Asia are undergoing a boom in new power plant and infrastructure construction to reduce the deficit between demand and supply of power. These countries are also witnessing strong deployments of variable generation technologies like wind and solar because of established targets for clean renewable energy coupled with falling prices. In the T\&D segment of the power sector, new high voltage direct current lines, high voltage $A C$ lines, power converters, reactive compensators, and others are being deployed alongside legacy assets. On the customer side, utilities are being pushed into unchartered territory with rooftop solar, storage, smart applications to control devices, and aggregation of loads for demand response. This transformation is resulting in changes to traditional diurnal and seasonal load profiles, and more frequent occurrence of sudden increase (clouds cover the solar panels) or drop (after the clouds pass) in demand. Operational optimization of such a complex network requires real-time data, analytics that optimizes the entire network and communicates the decisions to the generation, T\&D, and consumer devices. This is made possible by loT. It makes the grid intelligent and flexible, thereby giving it the capability to manage variability and uncertainty. ${ }^{14}$

13 General Electric. 2016. GE Power Digital. https://www.ge.com/digital/sites/default/files/Operations\%200ptimization\%20 Solution\%20Sheet.pdf

14 R. Young, J. McCue, and C. Grant. 2016. The Power is on: How loT Technology is Driving Energy Innovation. https://dupress.deloitte. com/content/dam/dup-us-en/articles/iot-in-electric-power-industry/DUP2727_loT_Electric-Power_MASTER.pdf 


\section{Comprehensive Customer Services and Experiences}

The earliest, most visible, and much publicized applications of loT are in the power sector-smart meter and smart thermostat.

Smart meters are internet-connected devices to send electricity consumption data to the utility over the internet (or other form of communication protocol). The transmission typically occurs every hour or more frequently. The smart meter also has a disconnect and connect switch, which is controlled by instructions sent through the internet. In newer incarnations a variety of add-on services are available:

(i) Portal for customers to manage usage, billing and other customer support issues. Portals have led to modest reduction in energy usage and higher reduction during peak events.

(ii) Net metering to sell power to the grid and prepaid purchase of electricity.

(iii) Data analytics applications for locating outages for faster restoration of power, identifying pilferage, dynamic pricing based on time of use, and others.

(iv) In addition to energy usage, smart meters can also send line voltage information, which is used to manage distribution voltage to reduce losses.

Three case studies of advanced metering infrastructure (AMI) along with quantification of the benefits are described in the next section.

Smart thermostats are internet connected devices that measure temperature and/or humidity inside a home or office and send the data to the cloud. A variety of machine learning applications have been developed to balance energy saving and user comfort. In addition, these devices allow authorized users to change the temperature setting of the thermostat on a smartphone. An extension of home-based applications of loT is energy efficiency in office buildings. Nest, a leading manufacturer of a learning thermostat, conducted an internal study and two independent studies and found that on average, US customers saved $10 \%-12 \%$ on their heating bills and about $15 \%$ on their cooling bills. ${ }^{15}$ Intel claims smart building loT solutions can yield $8 \%$ energy savings in year 1 and $20 \%-30 \%$ savings after year $1 .{ }^{16}$ According to Gartner, an integrated building management system that manages cooling, heating, and lighting can help reduce energy consumption by $50 \% .^{17}$

In Asia, several large pilots of smart meters are ongoing. Smart meters have the potential to significantly improve customer service through easier payments, enable better outage management, and reduce cost. Smart meters are enabling new business models for providing electricity in off-grid applications, thereby increasing energy access. Smart thermostats and smart meters in conjunction with other loT solutions have the potential to spur a variety of smart buildings and smart city applications.

Emerging loT applications include home-based smart energy management solutions with integrated management of generation, storage, and consumption. For instance, such a solution would integrate solar PV, storage, electric vehicle, and major appliances and through algorithms manage the buying, selling, and usage of power to achieve objectives like maximizing revenue or minimizing payment to utility. Consider a use case of SEMS in a region with high solar PV penetration and time-of-day price of

15 M. Rogers. 2015. Nest. https://nest.com/blog/2015/02/02/the-nest-learning-thermostat-saves-energy-heres-the-proof/

16 Intel. 2015. Intel loT Smart Buildings. https://www.intel.com/content/dam/www/public/us/en/documents/solution-briefs/ iot-ecs-tatung-reduce-carbon-footprint-solution-brief.pdf

17 Gartner. https://www.gartner.com/doc/reprints?id=1-3P9ZD7B\&ct=170103\&st=sg 
electricity. Examine a household with rooftop solar PV, storage, electric vehicle, and five loT-enabled devices-oven, icemaker, dishwasher, clothes washer, and dryer. Further consider a sunny day when the dynamic price of electricity has dropped because there is excess solar PV generation in the region. In this use case, the SEMS algorithm may decide to purchase cheaper power from the grid to power five preprogrammed appliances and store the energy from rooftop solar PV into the storage device and the EV for use during night. This SEMS application contains these components of loT:

(i) sensors to measure solar PV production, solar radiation, state of energy storage, state of electric vehicle, charge and others;

(ii) actuators to turn appliances on or off, switches, storage devices, and EV; and actuators to change settings of HVAC, refrigerator, and other devices;

(iii) data feed from external sources about dynamic price of electricity, weather forecast, and others;

(iv) algorithms to optimize buying and selling of electricity; and

(v) dashboard for customer to view energy usage.

Such SEMS systems for homes and buildings are not too far in the future and, with widespread adoption, would greatly complicate the current centralized utility model in which the flow of energy is unidirectional-from large centralized generation plants to customers. With a bidirectional flow of energy, an intelligent and flexible grid is required. ${ }^{18}$ Therefore, management of the entire grid will be a requirement in the not too distant future. loT is poised to solve this challenge.

\section{The Internet of Things in the Power Sector in Asia}

Utilities in Asia are facing a multitude of challenges including aging infrastructure, rising demand for electricity, poor reliability, unsustainably high aggregate technical and commercial losses, demands from regulatory commissions to keep tariffs low, and pressure from governments and lending agencies to reduce greenhouse gas emissions. The three categories of solutions are applicable to utilities is Asia. The last section, Next Steps, describes the process of developing a road map to chart strategic business initiatives to loT projects.

\section{CASE STUDIES}

The internet of things is an emerging field, therefore detailed case studies with rigorously computed long-term benefits are difficult to find. The case studies presented here are use cases that were implemented. In most cases benefits realized over the short-term are presented. In most cases, the cost information is not available.

\section{A. Asset Performance Management}

General Electric (GE) has implemented several loT solutions for asset performance management (APM). ${ }^{19}$ These are presented in Table 2.

18 R. Young, J. McCue, and C. Grant. 2016. The Power is on: How loT Technology is Driving Energy Innovation. https://dupress.deloitte. com/content/dam/dup-us-en/articles/iot-in-electric-power-industry/DUP2727_loT_Electric-Power_MASTER.pdf

19 General Electric. Advanced Analytics: The Core of Asset Performance Management (APM). https://ge-power.postclickmarketing. com/Global/FileLib/Executive_Brief/How_GE_Asset_Performance_Management_Reduces_Downtime_Executive_Brief.pdf 


\section{Table 2: Case Studies on Use of Internet of Things in Conventional Power Plants for Asset Performance Management}

\begin{tabular}{|c|c|c|}
\hline Plant & Solution & Benefits \\
\hline $\begin{array}{l}\text { Bord Gais, Ireland } \\
445 \mathrm{MW} \text { combined- } \\
\text { cycle gas power plant }\end{array}$ & $\begin{array}{l}\text { Goal: Continuous operation with no unplanned } \\
\text { downtime } \\
\text { (i) } 141 \text { total sensors around the plant to monitor } \\
\text { the condition of assets in the plant. } \\
\text { (ii) Early warning of failure mechanism resulting } \\
\text { in efficient outage management. }\end{array}$ & $\begin{array}{l}\text { (i) Reduce plant downtime. } \\
\text { (ii) Reduced BoP operations cost. } \\
\text { (iii) } € 2.28 \text { million positive financial impact } \\
\text { in year } 1 \text { from cost savings and cost } \\
\text { avoidance. }\end{array}$ \\
\hline $\begin{array}{l}\text { Scottish Southern } \\
\text { Energy, United } \\
\text { Kingdom } \\
\text { Thermal generation } \\
\text { fleet at } 11 \text { locations }\end{array}$ & $\begin{array}{l}\text { Goal: Increase plant availability through early } \\
\text { detection of potential failure and prevent past } \\
\text { failures from reoccurring. } \\
\text { (i) Created an Equipment Performance Center } \\
\text { to improve the reliability of its thermal fleet of } \\
\text { generators. } \\
\text { (ii) It continuously monitors combustion } \\
\text { dynamics, turbine vibration, boiler } \\
\text { temperature, creep and others at } 11 \text { different } \\
\text { locations and 1,026 assets. } \\
\text { (iii) Predictive analytics algorithms are deployed. }\end{array}$ & $\begin{array}{l}\text { Significant reduction in plant failures } \\
\text { resulting in increased availability and } \\
\text { production. } \\
\text { (i) Early failure detection has resulted in } \\
\text { savings of approximately } £ 3 \text { million per } \\
\text { year. } \\
\text { (ii) Overall insurance costs have been } \\
\text { reduced ( } £ 7.5 \text { million per year) and with } \\
\text { improved maintenance, a greater control } \\
\text { over capital expenditures is expected. } \\
\text { (iii) Savings of £100,ooo in repair costs by not } \\
\text { running the generator into a failed state. }\end{array}$ \\
\hline $\begin{array}{l}\text { Salt River Project, } \\
\text { Phoenix, Arizona, } \\
\text { United States } \\
11 \text { power plant locations } \\
\text { (Coal, gas, nuclear and } \\
\text { renewable) }\end{array}$ & $\begin{array}{l}\text { Goal: Integrate data across multiple plants for } \\
\text { outage management, to optimize maintenance } \\
\text { strategies and to understand where production } \\
\text { issues might occur next. }\end{array}$ & $\begin{array}{l}\text { High level of asset, plant, and fleet reliability. } \\
\text { Able to see problems before they happen- } \\
\text { toward no unplanned downtime and } \\
\text { improving fleet reliability. } \\
\text { \$0.5 million per year savings. }\end{array}$ \\
\hline
\end{tabular}

BoP = balance of plant, $\mathrm{MW}=$ megawatt.

Source: GE. Advanced Analytics: The Core of Asset Performance Management (APM). 2017. https://ge-power.postclickmarketing.com/ Global/FileLib/Executive_Brief/How_GE_Asset_Performance_Management_Reduces_Downtime_Executive_Brief.pdf

Two additional APM related case studies are presented below.

\section{Large European Electric Utility}

C3loT has deployed a predictive maintenance solution at a 700-megawatt (MW) coal-fired generation plant. More than 80 sensors are used to monitor, with 10-second frequency, steam turbine, main and booster water turbo pumps, and feedwater pump system. Data analytics like machine learning and pattern detection are used to predict sealing fluid loss and vibration-induced failures. The results of this deployment are 3-week advance notice of impending failures, which reduces cost of equipment failure by up to $€ 100,000$ per incident.

According to C3loT, the advantages of this capability are "Improving prognostic lead time and flexibility in scheduling of maintenance tasks; increasing temporal accuracy and localization of asset failure predictions; reducing or avoiding unplanned, emergency maintenance tasks; and maximizing energy production reliability and dispatch commitments." 20

20 C3IOT. Case Study: Predicting, Diagnosing, and Reducing Equipment Failures. http://c3iot.com/case-study/predictingdiagnosing-and-reducing-the-economic-impact-of-equipment-failures/ 


\section{Wind Farm in the United States}

Romax Technology reports on a case study of an 80-turbine wind farm with $2 \mathrm{MW}$ turbines. ${ }^{21}$ The analysis is specific to bearing failure in 10-year old machines that have a failure frequency of 2.91 per year. With condition monitoring system (CMS) and supervisory control and data acquisition (SCADA) data, three scenarios were presented with the associated total cost of failure (lost production + crane cost + refurbishment + labor + shipping + other):

- Scenario 1. No condition monitoring, no early detection and poor bearing availability. Total cost of failures is $\$ 905,000$.

- Scenario 2. Failures are detected by CMS and repairs done one-by-one (downtime is 4 days per turbine). Total cost of failures is $\$ 679,000$.

- Scenario 3. Failures are detected by CMS allowing scheduled repair for all bearings at the same time. Bearings are closely monitored and run to near failure. There is some downtime as turbine(s) may need to be shut down for repair all at once. The total cost of failure is $\$ 535,000$. Adoption of this third strategy would result in about $41 \%$ reduction in the cost of O\&M specific to bearing failure.

\section{B. Operational Optimization}

\section{Conventional Power Plants}

GE has implemented several loT solutions in generation plants. These are presented in Table 3.22

Table 3: Case Studies on Use of Internet of Things in Conventional Power Plants

\begin{tabular}{|c|c|c|}
\hline Plant & Solution & Benefits \\
\hline $\begin{array}{l}\text { A2A, Chivasso } \\
\text { Power Plant, Italy }\end{array}$ & $\begin{array}{l}\text { Goal: Improve plant flexibility-reduce minimum } \\
\text { load level, increase ramp rate, lower operating cost, } \\
\text { and reduce emissions. } \\
\text { Gather machine sensor data and apply analytics. } \\
\text { Operations optimization solution. }\end{array}$ & $\begin{array}{l}\text { (i) Higher flexibility of plant } \\
\text { (ii) High ramp rate }+/-50 \mathrm{MW} / \mathrm{min} \text {, allowing } \\
\text { it to meet large net demand } \\
\text { (iii) Lower operating cost, and lower fuel } \\
\text { consumption } \\
\text { (iv) Lower emissions } \\
\text { (v) Minimum time to startup } \\
\text { (vi) Compete in ancillary market: respond } \\
\text { in real time to obtain maximum } \\
\text { performance in response to market } \\
\text { pricing }\end{array}$ \\
\hline NRG, United States & $\begin{array}{l}\text { Goal: Optimize operation of plant by bidding } \\
\text { additional capacity during peak market prices. } \\
\text { (i) Balance peak firing (operating above operating } \\
\text { limit) with outage scheduling to maximize } \\
\text { profitability. } \\
\text { (ii) Digital twin model to adjust operating } \\
\text { conditions and key set points. }\end{array}$ & $\begin{array}{l}\text { (i) Potential for more than } \$ 5 \text { million of } \\
\text { additional profitability with no impact on } \\
\text { critical outage schedule }\end{array}$ \\
\hline
\end{tabular}

$\mathrm{MW}=$ megawatt.

Source: GE. Discover the Power of Digital Across the Electricity Value Network (EVN) Customer Stories. 2017 https://www.ge.com/digital/ sites/default/files/Discover-the-Power-of-Digital-Customer-Stories.pdf

21 A. Crowther, T. Eritenel and X. Ma. Wind Systems. 2012. "Improving Performance and Reliability with Condition Monitoring."

22 General Electric. Discover the Power of Digital Across the Electricity Value Network (EVN) Customer Stories. 2017. https://www. ge.com/digital/sites/default/files/Discover-the-Power-of-Digital-Customer-Stories.pdf 


\section{Optimization of Energy Production in Wind Farm}

Wind turbine manufacturers are offering a variety of services to maximize wind farm production using loT. This is accomplished by measuring wind speed, wind direction, pitch angle, yaw angle, power production, and other parameters at each turbine, and transmitting it to an loT hub for optimizing production of the wind farm as a whole.

One of the optimization involves reducing wake losses. In a wind farm, individual turbines are laid out to minimize wake along the primary direction of wind; when the wind direction is not along the primary direction, wake losses increase. ${ }^{23}$ Wake reduces wind speed and induces higher turbulence leading to lower production by turbines in the wake. Decreasing wake losses even when the wind direction is not in the optimal direction is one of the higher value loT applications. Envision has developed a solution that combines data from radar and SCADA with computational fluid dynamics models to adjust pitch of blades and yaw of turbines to increase the energy production of the wind farm. ${ }^{24}$

GE's PowerUp initiative is another successful example of use of real time measurements to enhance annual energy production of wind farms using wake loss optimization and other site-specific adjustments. ${ }^{25}$ Since its initial release in 2013 which was primarily based on historical data analysis, a new enhanced version was released in 2016 that incorporates real time data. According to GE, the new version of PowerUp uses "iterative tuning process to monitor a site's specific wind environment and lock in the appropriate settings based on the most current information available." At wind speeds that are higher than the rated value, the power output is increased above the rating by adjusting the generator speed and gearbox torque, while ensuring that the stress and fatigue loading of the turbine are within acceptable level. For lower than rated wind speeds, the blade pitch, tip speed, and yaw position are adjusted to change the power curve to yield a higher power output. GE claims a 5\% to 10\% increase in annual energy production as a result of PowerUp. GE has implemented it at wind farms owned by E.ON, EDF Renewables, First Wind, and others.

\section{Smart Buildings, Smart Meters, and Smart Consumer Applications}

In this case study, results from the United States Department of Energy implementation of Advanced Metering Infrastructure in three cities are presented in Table $4 .{ }^{26}$

\section{Table 4: Case Studies on Advanced Metering Infrastructure Implementation Funded by the United States Department of Energy}

\begin{tabular}{|l|l|l|}
\hline \multicolumn{1}{|c|}{ Location } & \multicolumn{1}{c|}{ Description } & \multicolumn{1}{c|}{ Benefits } \\
\hline $\begin{array}{l}\text { Glendale, } \\
\text { California } \\
\text { (population: } \\
194,000)\end{array}$ & $\begin{array}{l}\text { 46,000 users with AMI and } \\
\text { customer portal to monitor } \\
\text { home energy usage }\end{array}$ & $\begin{array}{l}\text { Total customer savings: } 5,777 \mathrm{MWh} \text {, which is a } 2 \%-4 \% \text { reduction in } \\
\text { usage. } \\
\text { Overall load reduction of } 4.1 \% \text { during peak hours across } 38,000 \text { homes } \\
\text { by notifying customers of peak event; no price incentives were offered. } \\
\text { Overall \$24 million in positive value for an IRR of } 11.5 \% .\end{array}$ \\
\hline
\end{tabular}

continued on next page

23 P. Jain. 2016. Wind Energy Engineering. New York: McGraw-Hill.

24 J. Shah. 2016. Optimizing Energy Production: Addressing Rotor Wakes at Wind Farms. http://www.windpowerengineering.com/ construction/simulation/optimizing-energy-production-addressing-rotor-wakes-wind-farms/

25 P. Dvorak. 2016. GE Renewable Energy Introduces New Suite of Digital Wind Farm Apps. http://www.windpowerengineering. com/featured/business-news-projects/ge-renewable-energy-introduces-new-suite-digital-wind-farm-apps/

26 US Department of Energy Smart Grid Program. 2014. Municipal Utilities' Investment in Smart Grid Technologies Improves Services and Lowers Costs. https://energy.gov/sites/prod/files/2014/10/f18/SG-Utilitylnvestment-Oct2014.pdf 
Table 4 continued

\begin{tabular}{|c|c|c|}
\hline Location & Description & Benefits \\
\hline $\begin{array}{l}\text { Burbank, } \\
\text { California } \\
\text { (population: } \\
\text { 108,000) }\end{array}$ & $\begin{array}{l}50,000 \text { users with } \mathrm{AMI}, \text { smart } \\
\text { thermostats, distribution } \\
\text { automation at } 100 \text { feeders, and } \\
\text { load management }\end{array}$ & $\begin{array}{l}\text { Total customer savings: } 4,800 \mathrm{MWh} \text {, which is } 1 \%-2 \% \text { reduced usage } \\
\text { Field service requests were reduced from } 2,500 \text { to } 300 \text { per month } \\
\text { Exceptional system reliability: } 15 \text { minutes of outage once every } \\
5.4 \text { years compared to industry average of } 96 \text { minutes every } 1.2 \text { years. } \\
\text { System average interruption frequency index was reduced from } 0.34 \text { in } \\
2009 \text { to } 0.24 \text { in } 2013 \text {, and system average interruption duration index } \\
\text { was reduced from } 27.8 \text { in } 2009 \text { to } 9.5 \text { in } 2013 \text {. }\end{array}$ \\
\hline $\begin{array}{l}\text { Danvers, } \\
\text { Massachusetts } \\
\text { (population: } \\
26,000 \text { ) }\end{array}$ & $\begin{array}{l}13,000 \text { smart meters, customer } \\
\text { portal, net-metering for } \\
\text { distributed generation and } \\
\text { time-of-day rates. }\end{array}$ & $\begin{array}{l}\text { Deferral of } \$ 3 \text { million of investment in distribution capacity for up to } \\
25 \text { years. } \\
\text { Volume of customer service calls decreased by about } 75 \% \text {. } \\
\text { Reduced annual truck rolls by } 40 \% \text { for meter rereads, connect, and } \\
\text { disconnect. }\end{array}$ \\
\hline
\end{tabular}

$\mathrm{AMI}=$ advanced metering infrastructure, IRR = internal rate of return, $\mathrm{MWh}=$ megawatt hour.

Source: US Department of Energy Smart Grid Program. 2014. Municipal Utilities'Investment in Smart Grid Technologies Improves Services and Lowers Costs. https://energy.gov/sites/prod/files/2014/10/f18/SG-Utilitylnvestment-Oct2014.pdf

According to ABI Research, Smart Meters are the largest loT application segment in the People's Republic of China (PRC). ${ }^{27}$ In 2015 and 2016, 150 million and 160 million smart meters were shipped in the PRC, with a projected annual growth rate of $8 \%{ }^{28}$ The impetus for smart meters is the implementation of ladder pricing system and inability of older meters to capture point-of-time consumption data. 'Benefits or data on implementation of smart meters in the PRC are not available.

In other parts of Asia, smart meter projects are in infancy stages, with high profile announcements from Singapore Power, Electricity Generation Authority of Thailand, TNB of Malaysia, Bangalore Electricity and Supply Company, Tata Power Delhi Distribution, and Manila Electric Company (Meralco).

\section{CHALLENGES}

The challenges faced by the internet of things (IoT) are similar to the challenges faced by any business and technological transformation. Since the electricity sector touches most of the society, from the megacities to the remotest villages, the challenges are big. The challenges are grouped into three categories:

(i) Customer expectations. With loT, technology-savvy customers with the highest kilowatt-hour usage are leading the transformation across the world. In most Asian countries, the price of electricity is high (demand charges) for high-tier usage and as a result, the return on investment on smart devices is high. At the residential level, high-usage consumers will therefore adopt smart devices even without any incentives. The challenge will be to encourage the middle-tier and lower-tier electricity users to adopt these technologies and to enjoy the benefits of loT in terms of lower electricity bills and higher reliability. From the utility standpoint, the challenge is to ensure that the investment in loT ultimately reduces tariff for middle- and lower-tier customers,

27 IOT Business News. 2016. China's Overbearing Share of Smart Meter Connections Portends Future Issues for Its loT Competitiveness. https://iotbusinessnews.com/2016/10/19/97002-china-overbearing-share-smart-meter-connectionsportends-future-issues-iot-competitiveness/

28 PR Newswire. 2016. China Smart Meter Industry Report, 2016-2020. http://www.prnewswire.com/news-releases/chinasmart-meter-industry-report-2016-2020-300374022.html 
whether the investment is for operational optimization, asset performance management, or customer engagement.

(ii) Regulations. As with any technology, adoption and realization of benefits depends on regulations. The regulatory framework will have to address three new aspects that have not been traditionally addressed by utilities: cybersecurity, data privacy, and interoperability.

- loT will create a large number of access points through which intruders and hackers can compromise the security of the national grid and customers' facilities. Cybersecurity is a moving target and could paralyze policy makers into either adopting such stringent requirements that cause loT projects to grind to a halt because it is not implementable or setting the bar too low. Policy makers need to address this by studying and tracking security issues, and adapting international standards.

- Privacy of customer data will become a pressing issue with loT because of the large amount of usage data that will be collected by smart meters. Policy makers have to specify guidelines for collection, storage, access, and usage of this data.

- Regulatory bodies can enable rapid and smooth adoption of loT by specifying standards for interoperability of loT devices and systems.

- Beyond these new aspects of regulation, the traditional list of regulatory changes that will be required include effective separation of monolithic utilities into distribution, transmission, and generation functions; competition in each of the three verticals; realignment or elimination of subsidies; day-of-time tariff; netmetering for small-scale renewable energy projects; demand response; intercommunity and intracommunity trading of electric energy; and grid code changes that encourage flexibility in the grid. These regulatory changes are required to align the objectives of utilities with higher efficiency, reliability and customer engagement, and lower emissions.

(iii) Investments. loT implementation and rollout will require investment to unlock the monetary and societal benefits. loT investments at generation plants and transmission and distribution (T\&D) networks would have to be funded by the government-owned utilities, in order to improve reliability, efficiency, and emissions. For independent power producer (IPP) plants, investment in loT could become the cost of doing business if the regulators mandate and enforce operational requirements, like two-way communication (send data and receive commands), inclusion in automatic generation control, and others that allow operational optimization. In addition, reliability requirements for IPP generators would incentivize IPPs to make investments in APM. An outcomes-based model for investment has evolved for loT projects. In this model, the utility pays no or small upfront fees, but pays for the project by sharing in the benefits that are derived from the loT solution. Such a model has the promise to reduce capital outlays, share the risk, and align the goals of the solution provider with that of the utility. Lack of conditions to make such a modality work because of large losses and poor balance sheet in many developing countries is a challenge.

(iv) Retraining of workforce. Large technology changes introduce large productivity improvements and market disruptions, resulting in large labor force dislocations. loT has the potential to make some of the repetitive jobs redundant, but open up new jobs in higher skill areas like hardware designers, software engineers, data scientists, and others. Satisfying this need will require a major shift in education and training of the workforce. 
(v) Standards of IoT. Utilities have spent large sums on smart meters that are only compatible with a certain technology or equipment provider. This has locked them into a particular set of equipment that may not be the best suited for integration with other initiatives and for future rollout of the solution. Since IoT as a discipline is new, the standards development is in a nascent stage. Most of the standards have been borrowed from other initiatives and some of the standards bodies are consortia, attempting to standardize IOT applications in devices. Some of the most prominent standards or standards groups are listed below:

- IEEE P2413 group formed in 2014 has developed an architectural framework that promotes coordination and uniform application of IOT components across various sectors..$^{29}$

- Open Connectivity Foundation is an organization that develops specifications for loT devices used in multiple domains such as consumer electronics, and industrial automation. ${ }^{30}$ The consortium also runs a certification program for its members.

- Open ADR Alliance is a standard for automated demand response..$^{31}$ It utilizes past standards like Organization for the Advancement of Structured Information Standards, Utilities Communications Architecture, and North American Energy Standards Board. Open ADR standardizes the message format used for Auto-DR so that dynamic price and reliability signals can be delivered in a uniform and interoperable fashion among utilities, ISOs, and energy management and control systems.

- Zigbee is a standard for interoperable products that monitor, control, inform, and automate. ${ }^{32}$ Zigbee Smart Energy is used for smart meters and smart grid applications.

- Industrial Internet Consortium: This is not a standard-setting group. It aims to create "test beds" to demonstrate the use of loT in power plants. ${ }^{33}$

\section{WAY FORWARD FOR THE ASIAN DEVELOPMENT BANK}

Sustainable growth of developing member countries (DMCs) of the Asian Development Bank (ADB) hinges on efficient and low-carbon power generation and access to electricity for the poor. The internet of things (loT) presents tremendous opportunities to accomplish this at the DMCs in the power sector. ADB can play a role in investment, capacity building, and knowledge solutions.

\section{A. Investment}

For investments made by ADB in new power plants, substations, advanced metering infrastructure (AMI) and other parts of the grid, due care should be exercised to ensure that initiatives that focus on the longer-term issues are not ignored. Often the emphasis is on civil works and commissioning of the plant so that energy production starts on time and other parts of the project are deemphasized or ignored that have longer-term benefits like installing sensors, telemetry, connecting to SCADA systems, and utilizing the full capabilities of the SCADA system. These systems enable condition monitoring of equipment and data analytics to optimize performance and reduce life cycle cost.

29 IEEE Standards Association. Standard for an Architectural Framework for the Internet of Things. http://grouper.ieee.org/ groups/2413/

30 Open Connectivity Foundation. https://openconnectivity.org/

31 Open ADR Alliance. http://www.openadr.org

32 Zigbee Alliance. Utility Industry. http://www.zigbee.org/what-is-zigbee/utility-industry/

33 Industrial Internet Consortium. http://www.iiconsortium.org/ 
Similarly, for retrofits or upgrades to existing power plants, substations, and other parts of the grid, ADB should exercise due care to ensure that the changes include loT components so that sensor data and data analytics are used to optimize performance and do predictive maintenance. These initiatives enhance reliability and efficiency, and reduce emissions.

Most loT projects related to operational optimization are being financed by the vendor with low or no upfront investment by the buyer and the vendor is paid from the derived benefits. This presumes that the buyer uses a well-established accounting standard for cost allocation. Furthermore, in most DMCs, government provides subsidies to both private and public utilities, and the attribution of subsidy to a cost category is ambiguous. Given these ambiguities, in an outcome-based investment scheme, it may not be clear how much benefit was derived and how much should be assigned to the loT project. It is imperative that $\mathrm{ADB}$ consider providing assistance to resolve such issues to attract investment for loT initiatives.

\section{B. Capacity Building}

There are several aspects to capacity building that are specific to loT.

(i) Organization. Leading-edge power companies are creating a new position in the organization called the chief digital officer (CDO) and an organization structure to support the loT efforts. Often, a CDO is also called a "transformer-in-chief' because loT has the potential to radically transform an existing business and create new businesses. Since loT touches almost all aspects of a business, the loT organization cuts across traditional departments. In the power sector, this organization would be charged with managing the digital devices in the field (generation, transmission and distribution and customers' meters) to collect data, data integrity and quality, maintenance planning, operational planning, cybersecurity, data analytics, building custom applications, and keeping track of the key performance indicators of the grid. Notice that this organization is cutting across traditional silos in a utility. In addition, some of the key business processes would require redesigning, such as operation and maintenance, customer connect and disconnect, unit commitment and economic dispatch, and medium-term and long-term planning.

(ii) Employee training. loT promises to automate labor-intensive tasks like meter reading, customer connect and disconnect, customer service, outage detection, and others. According to a United States Department of Energy report: "The electricity system of the 21st century will require an adaptable and flexible workforce with additional areas of expertise and capabilities than the current workforce. ${ }^{34}$ The integration of variable renewable sources, storage systems, smart grid, and demand management will require new training and skillsets. ... As an example of these new workforce needs, the increased ICT component in the smart grid of the 21st century requires a wide array of new and different skills." In Asia, managing the workforce transformation is likely to be one of the most vexing problems of loT implementations.

(iii) Standards. ADB may consider providing interventions such as technical assistance and loans to advise on technical standards for overall architecture, communication protocol, data exchange methods and formats, and overall security of devices, communication, data, and platform.

34 US Department of Energy. 2017. Chapter V: The Electricity Workforce: Changing Needs, New Opportunities. https://energy. gov/sites/prod/files/2017/01/f34/Chapter\%205\%20The\%20Electricity\%20Workforce\%20Changing\%20 Needs,\%20 New\%20Opportunities_0.pdf 
(iv) Customer outreach. The success of smart meter initiatives largely depends on customer acceptance. Often, customers have misconceptions about smart meters-electricity rates will rise and the utility will disconnect service quicker in case of late payment. The outreach campaign should clear up the misconceptions and present the benefits. The best practices for customer education and communication were documented by BGE. ${ }^{35}$ It presents a threephase approach:

a. Phase 1. Introductory region-wide communication initiative to educate customers about smart meters.

b. Phase 2. Targeted customer communication for customers who will receive smart meters.

c. Phase 3. Education campaign to show use of customer portal, generation of home energy reports, and use of data and report to understand energy usage and to modify energy consumption.

In each phase, a variety of media are used including, advertisements on billboards, radio and television, community meetings, postcards and messages on smart phones.

\section{Tangibility of Knowledge Solutions}

Implementing loT-based integrated sensor networks can also showcase tangible value addition, and knowledge product in development interventions. By undertaking appropriate ICT architecture, the sensor network of loT can be reused or shared with other power plants as well. Cross leveraging such networks with other public utility systems is also a possibility.

\section{Asian Development Bank's Smart Grid Projects}

ADB has made significant commitments to smart grid and smart meter projects, as listed below.

(i) Technical assistance grant to the People's Republic of China of \$1.2 million for developing smart grid technology for efficient utilization of renewable energy.

(ii) Loan program in Uzbekistan of $\$ 150$ million for the Advanced Electricity Metering Project (Phase 1). This involved installation of modern, accurate, theft-proof digital meters for 1 million residential and small commercial power users in the cities of Bukhara, Jizzakh, and Samarkand.

(iii) Loan program in Uzbekistan of $\$ 300$ million for the Advanced Electricity Metering Project. This continued the installation of advanced metering infrastructure in Andijan, Fergana, Kashkadarya, Namangan, and Surkhandarya.

(iv) Loan program in India of $\$ 500$ million in sovereign loan and $\$ 500$ million in nonsovereign loan for the Green Energy Corridor and Grid Strengthening Project. This included real-time measurement and monitoring equipment, $800 \mathrm{kV}$ high voltage direct current terminals, and $320 \mathrm{kV}$ high voltage direct current.

35 BGE. 2011. BGE Smart Meter Customer Education and Communication Plan. https://www.smartgrid.gov/files/060111BGESmartMeterCommPlanFINAL.pdf 
(v) Loan to Maldives of $\$ 124$ million for Preparing Outer Islands for Sustainable Energy Development (Phase 1). This involved design and installation of equipment for solar-diesel hybrid grids with rechargeable battery on about 160 islands.

(vi) Loan to Pakistan of $\$ 380$ million (ordinary capital resources) and $\$ 20$ million (Asian Development Fund) for the Second Power Distribution Enhancement Investment Program (Tranche 1). The investment program's objective is to introduce AMI in Pakistan's different distribution companies. There are nine distribution companies in Pakistan and the AMI rollout to these distribution companies will be in phases.

\section{NEXT STEPS}

The internet of things should not be treated as or considered a technology initiative. It should start with a road map that converts the highest level strategic business goals of the utility to short-, medium- and long-term initiatives for transformation. The initiatives then drive the value proposition for specific loT pilot projects. Without such an approach, it is easy to be swayed by vendor driven projects or the "shiny thing," which would squander investments in loT projects. Often, the first few loT pilots need a few or no additional sensors, while the focus of the pilots is to use existing data in smarter ways. A three-phase approach is illustrated in Figure 9.

Figure 9: A Phased Value-Driven Approach to Internet of Things Projects

Phase 1: Single equipment, existing data

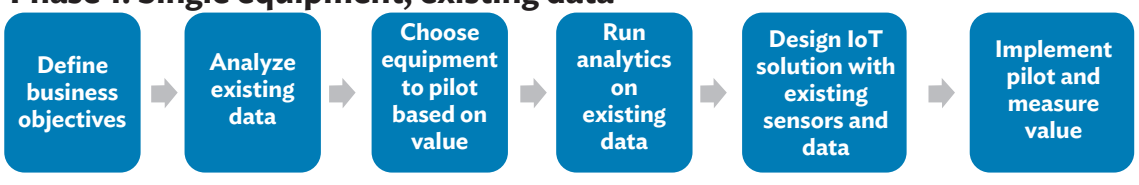

Phase 2: Single equipment, new sensors

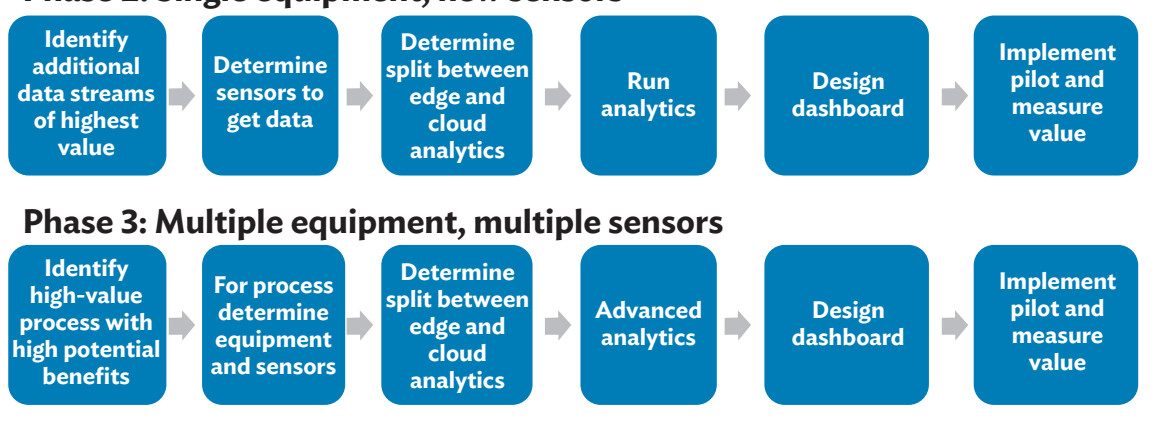

IoT = Internet of Things.

Source: Asian Development Bank. 
Utilities in Asia and the Pacific are facing a multitude of challenges including aging infrastructure, rising demand for electricity, poor reliability, unsustainably high aggregate technical and commercial losses, demands from regulatory commissions to keep tariffs low while achieving profitability, and pressure from governments and lending agencies to reduce greenhouse emissions. These strategic goals must be converted to short-, medium- and long-term initiatives for transformation and then to loT projects. The process of developing an loT road map would consist of the following:

(i) Key people. Formulate a team comprising of people from different parts of the organization, and create a steering committee of department heads and the chief executive officer.

(ii) Business case. Connect with major strategic initiatives, e.g., loss reduction, reliability improvement, cost reductions, emissions reductions, renewable energy goal attainment, new metering, and others.

(iii) Processes. Create new loT-enabled processes to improve performance.

(iv) Technology. Work with operational and information technology that are available and/or represented in the country.

There are several methodologies for developing the road map. Since an organization has ongoing initiatives, it is useful to map these initiatives to the level of maturity that would be attained and to repurpose these initiatives to achieve a higher level of maturity. The plan, priorities, and progress of loT initiatives may be mapped using an outline illustrated in Table $5 .{ }^{36}$

Table 5: Illustration of a Structured Methodology for Mapping the Plan, Priorities, and Progress of an Internet of Things Initiative

\begin{tabular}{|c|c|c|c|c|c|}
\hline \multicolumn{6}{|c|}{ Increasing level of maturity or sophistication } \\
\hline Domains & Initiating & Enabling & Integrating & Optimizing & Pioneering \\
\hline $\begin{array}{l}\text { Strategy } \\
\text { Management } \\
\text { and } \\
\text { Regulatory }\end{array}$ & $\begin{array}{l}\text {-Vision exists } \\
\text {-Concept projects } \\
\text {-Discussions with } \\
\text { regulator }\end{array}$ & $\begin{array}{l}\text {-Business plan } \\
\text { approved } \\
\text {-Budgets } \\
\text { established } \\
\text {-Funding of POC }\end{array}$ & $\begin{array}{l}\text {-Vision and } \\
\text { strategy in place } \\
\text {-Governance } \\
\text { model } \\
\text {-Authorization for } \\
\text { investment }\end{array}$ & $\begin{array}{l}\text { - Vision and } \\
\text { strategy driving } \\
\text {-Core } \\
\text { competency } \\
\text {-All stakeholders } \\
\text { involved }\end{array}$ & $\begin{array}{l}\text {-New services } \\
\text { and/or products } \\
\text {-Benefits are } \\
\text { reinvested } \\
\text {-New business } \\
\text { model emerges }\end{array}$ \\
\hline \multicolumn{6}{|c|}{ Organization structure } \\
\hline \multicolumn{6}{|l|}{$\begin{array}{l}\text { Grid } \\
\text { operations }\end{array}$} \\
\hline $\begin{array}{l}\text { Work and asset } \\
\text { management }\end{array}$ & & & & & \\
\hline
\end{tabular}

continued on next page

36 Software Engineering Institute, Carnegie Mellon. 2010. Smart Grid Maturity Model. http://www.sei.cmu.edu/smartgrid/ 
Table 5 continued

\begin{tabular}{|c|c|c|c|c|c|}
\hline \multicolumn{6}{|c|}{ Increasing level of maturity or sophistication } \\
\hline Domains & Initiating & Enabling & Integrating & Optimizing & Pioneering \\
\hline Technology & $\begin{array}{l}\text { - Enterprise ICT } \\
\text { architecture } \\
\text { exists or under } \\
\text { development } \\
\text { - ICT architectures } \\
\text { have been } \\
\text { evaluated for loT } \\
\text { apps } \\
\text { - Opportunities } \\
\text { are identified to } \\
\text { improve dept. } \\
\text { performance } \\
\text { - Technology } \\
\text { selection is } \\
\text { aligned with } \\
\text { loT vision and } \\
\text { strategies }\end{array}$ & $\begin{array}{l}\text { - Tactical ICT } \\
\text { investments are } \\
\text { aligned to an } \\
\text { enterprise ICT } \\
\text { architecture. } \\
\text { - Changes to the } \\
\text { enterprise ICT } \\
\text { architecture that } \\
\text { enable loT are } \\
\text { being deployed. } \\
\text { - Standards are } \\
\text { selected within } \\
\text { the enterprise } \\
\text { ICT architecture. } \\
\text { - A common } \\
\text { technology } \\
\text { evaluation and } \\
\text { selection process } \\
\text { is applied } \\
\text { - There is a data } \\
\text { communications } \\
\text { strategy for the } \\
\text { grid. } \\
\text { - Pilots based on } \\
\text { connectivity to } \\
\text { distributed IEDs } \\
\text { are under way. } \\
\text { - Security is built } \\
\text { into all initiatives } \\
\text { from the outset. }\end{array}$ & $\begin{array}{l}\text { - Smart grid- } \\
\text { impacted } \\
\text { business } \\
\text { processes are } \\
\text { aligned with the } \\
\text { enterprise ICT } \\
\text { architecture. } \\
\text { - Systems adhere } \\
\text { to an enterprise } \\
\text { ICT architectural } \\
\text { framework. } \\
\text { - loT technology } \\
\text { has been } \\
\text { implemented } \\
\text { to improve } \\
\text { cross-LOB } \\
\text { performance. } \\
\text { - The use of } \\
\text { advanced } \\
\text { distributed } \\
\text { intelligence } \\
\text { and analytical } \\
\text { capabilities are } \\
\text { enabled. } \\
\text { - The organization } \\
\text { has an advanced } \\
\text { sensor plan. } \\
\text { - A detailed data } \\
\text { communication } \\
\text { strategy and } \\
\text { tactics across } \\
\text { functions exists }\end{array}$ & $\begin{array}{l}\text { - Data flows end } \\
\text { to end from } \\
\text { customer to } \\
\text { generation. } \\
\text {-Business } \\
\text { processes are } \\
\text { optimized by } \\
\text { leveraging the } \\
\text { enterprise ICT } \\
\text { architecture. } \\
\text { - Systems have } \\
\text { sufficient wide- } \\
\text { area situational } \\
\text { awareness to } \\
\text { enable real-time } \\
\text { monitoring } \\
\text { and control for } \\
\text { complex events. } \\
\text { - Predictive } \\
\text { modeling and } \\
\text { near real-time } \\
\text { simulation are } \\
\text { used to optimize } \\
\text { support } \\
\text { processes. } \\
\text { - Performance } \\
\text { is improved } \\
\text { through } \\
\text { sophisticated } \\
\text { systems that are } \\
\text { informed by loT } \\
\text { data. } \\
\text { - Security strategy } \\
\text { and tactics } \\
\text { continually } \\
\text { evolve based } \\
\text { on changes in } \\
\text { the operational } \\
\text { environment } \\
\text { and lessons } \\
\text { learned. }\end{array}$ & $\begin{array}{l}\text { - Automatic } \\
\text { computing and } \\
\text { machine learning } \\
\text { are implemented } \\
\text { - Enterprise ICT } \\
\text { infrastructure } \\
\text { can } \\
\text { automatically } \\
\text { identify, mitigate, } \\
\text { and recover from } \\
\text { cyber incidents }\end{array}$ \\
\hline \multicolumn{6}{|c|}{ Customer } \\
\hline \multicolumn{6}{|l|}{$\begin{array}{l}\text { Value chain } \\
\text { integration }\end{array}$} \\
\hline $\begin{array}{l}\text { Societal and } \\
\text { environmental }\end{array}$ & & & & & \\
\hline
\end{tabular}

IED = intelligent electronic device, ICT = information and communication technology, loT = Internet of Things, LOB = lines of business, $P O C=$ proof of concept.

Source: Adapted from Software Engineering Institute. Carnegie Mellon University. Smart Grid Maturity Model. http://www.sei.cmu. edu/smartgrid/ 
When choosing projects, the focus of the utilities in Asia should be as follows:

(i) Start small and develop projects with high impact to build experience and confidence.

(ii) Develop pilots with support from vendors and integrators.

(iii) Use already developed project design templates from energy efficiency and performance improvement projects that are part of smart grid or similar initiatives.

(iv) Focus on projects that yield high expected internal rate of return or return on investment.

(v) Focus on asset monitoring across single asset types, e.g., gas-fired combined cycle plants, or high-voltage or medium-voltage grids.

IoT has the potential to unlock a vast amount of benefits to all the stakeholders of the power sector. From the generation and transmission and distribution (T\&D) perspective, an loT solution would digitize the power plant and substation with sensors to monitor and enable analytics to optimize the operational and maintenance aspects of the process. Operationally, the results would be significantly higher efficiency of production and lower emissions. From a maintenance perspective, the results would be lower cost of maintenance, higher reliability, and overall lower life cycle cost of equipment. Furthermore, loT promises to enhance the flexibility of generation and T\&D so that higher penetration of variable power (wind and solar) can be achieved. On the generation side, it can enable plants to run at lower capacity factors and provide higher ramp rates. On the T\&D side, it can reduce congestion and manage voltage at nodes to minimize transmission losses. Overall, through real-time data from a network of sensors and powerful analytics, the entire network can be optimized for efficiency, flexibility, availability, and emissions.

Smart meters, smart appliances, and variety of applications on smart phones are customer-centric IoT solutions that are poised to radically transform the relationship between traditional utilities and consumers. The conventional utility model consists of centralized generation and operations, and sale of product (electricity). The new utility model will be a decentralized model with two-way flow of electricity and sale of services. The services delivered by the utility will be information servicescustomer portal, usage data, time of day pricing, peak events, off-peak events, and others. Consumers will use this information for demand response and energy efficiency. A utility may provide other services like installation and maintenance of solar PV, storage units, and other electrical equipment, which are its core competency.

IoT transformation is inevitable but the journey to realizing the potential in Asia and the Pacific is likely to be difficult initially. The Asian Development Bank can play a big role in this transformation by designing appropriate development interventions such as technical assistance, loan, and equity. The results of this endeavor in the power sector would lead to higher energy access for the poor, lower emissions, and higher efficiency and reliability. 


\section{The Internet of Things in the Power Sector}

Opportunities in Asia and the Pacific

In Asia's power sector, grids are plagued with unreliable service and are struggling to upgrade power systems to keep up with high demand growth rates. The Internet of Things (loT), billed as the next industrial revolution or Industry 4.0, has the potential to significantly transform the power sector by optimizing operations, managing asset performance, and engaging customers to lower energy cost. The power sector is already reaping benefits from early consumer-oriented loT applications: smart meters and smart thermostats. Find out why Asia and the Pacific should rethink-despite loT adoption drawbacks - the importance of loT in terms of the tremendous opportunities and societal benefits it presents.

\section{About the Asian Development Bank}

ADB's vision is an Asia and Pacific region free of poverty. Its mission is to help its developing member countries reduce poverty and improve the quality of life of their people. Despite the region's many successes, it remains home to a large share of the world's poor. ADB is committed to reducing poverty through inclusive economic growth, environmentally sustainable growth, and regional integration.

Based in Manila, ADB is owned by 67 members, including 48 from the region. Its main instruments for helping its developing member countries are policy dialogue, loans, equity investments, guarantees, grants, and technical assistance. 